\title{
UN PRECEDENTE JUDICIAL PARA EL RECONOCIMIENTO DEL DESPLAZAMIENTO FORZADO INTERNO EN EL SALVADOR
}

Abraham A. Abrego Hasbún

\author{
Recibido: 29/07/2019 - Aceptado: 14/08/2019
}

\section{Introducción}

Con fecha 13 de julio de 2018, la Sala de lo Constitucional de El Salvador emitió sentencia en el Proceso de Amparo N. ${ }^{\circ}$ 411-2017, la cual establece un precedente latinoamericano en materia de desplazamiento forzado interno. ${ }^{1}$

El Amparo fue presentado por una familia víctima de desplazamiento forzado, acompañada por la organización Cristosal. La familia compuesta por 33 personas comenzó a ser sujeta de ataques por miembros de una pandilla, debido a que dos de sus miembros eran soldados; esto les obligó a desplazarse en varias ocasiones, con múltiples violaciones a sus derechos humanos.

A pesar de que las autoridades policiales y fiscales tuvieron conocimiento de los hechos y de los riesgos que sufría el grupo familiar, no desarrollaron en forma diligente las investigaciones y no activaron medidas de protección adecuadas. Lo anterior motivó la presentación de la demanda de amparo.

En los últimos 30 años, El Salvador ha pasado por un proceso de transición democrática caracterizado por la violencia. Solo en los últimos diez años, el país se ha posicionado en los primeros lugares en los índices de homicidio, lo cual ha generado el incremento del desplazamiento forzado. A pesar de ello, el Estado salvadoreño no ha reconocido el fenómeno y carece de marcos legales, programas y políticas para la protección y asistencia humanitaria de víctimas de desplazamiento forzado interno.

La relevancia de esta sentencia es que reconoce el desplazamiento forzado interno por violencia, con lo cual se reivindica a las víctimas, generalmente invisibilizadas. La Sala desarrolla en su sentencia un análisis de contexto sobre la migración forzada y sobre violencia en el país; concluye que existe un contexto de violencia e inseguridad que afecta gravemente a colectivos vulnerables de distintas zonas geográficas del país controladas por las pandillas que los obligan a desplazarse y que provocan afectaciones sistemáticas a sus derechos fundamentales. 
La Sala consideró que la situación que vive este colectivo de personas constituye un estado de cosas inconstitucionales, retomando la jurisprudencia colombiana en la materia. El impacto de la sentencia es que considera sus efectos erga omnes al estar ante una situación generalizada de vulneración de derechos de un grupo, por lo cual favorece a todas las personas en situación de desplazamiento y no solo a los demandantes.

La sentencia les ordena a las autoridades salvadoreñas, en un plazo de seis meses, reconocer a las víctimas de la violencia y del desplazamiento forzado como sujetos de derechos. Esto supone la revisión y emisión de legislación especial orientada a la protección de víctimas y testigos.

\section{Sentencia de Amparo Referencia 411-2017}

\section{Amparo}

Sala de lo Constitucional de la Corte Suprema de Justicia. San Salvador, a las diez horas con cuatro minutos del día trece de julio de dos mil dieciocho.

El presente proceso de amparo ha sido promovido por quienes en la presente sentencia, por motivos de confidencialidad y de seguridad en atención al art. 10 letra a) de la Ley Especial para la Protección de Víctimas y Testigos (LEPVT), serán identificados únicamente como Demandantes 1, 2, 3, 4, 5 y 6, representados en este proceso por medio de sus apoderados, en contra del jefe de la División Central de Investigaciones, del jefe de la División Antiextorsiones, del jefe de la Subdelegación de Berlín, todos ellos de la Policía Nacional Civil (PNC), del jefe de la Unidad de Vida e Integridad Física de la Oficina Fiscal de Mejicanos, del titular del Ministerio de Justicia y Seguridad Pública (MJSP), de la Asamblea Legislativa, de la Comisión Coordinadora y de la titular de la Unidad Técnica Ejecutiva (UTE) del Sector de Justicia, por la vulneración de sus derechos fundamentales a la seguridad material, a la protección familiar, a la protección jurisdiccional y no jurisdiccional, a la propiedad y a la libertad de circulación, reconocidos en los arts. 2 , inc. $1^{\circ}, 5$ incs. $1^{\circ}$ y $2^{\circ}$ y 32 de la $\mathrm{Cn}$.

Han intervenido en la tramitación de este amparo, como autoridades demandadas, el titular del MJSP, por medio de su apoderado, la Comisión Coordinadora y la titular de la UTE del Sector de Justicia, ambas por medio de su apoderado, la Asamblea Legislativa y la Junta Directiva de dicho órgano, por medio de sus apoderados, el Director de la PNC, por medio de sus apoderados, el jefe de la División Antiextorsiones, el jefe de la División Central de Investigaciones de la PNC, ambos por medio de su apoderada, el jefe de la Subdelegación de Berlín de la PNC, la jefa de la Unidad de Vida e Integridad Física de la Oficina Fiscal de Mejicanos y el titular de la Fiscalía General de la República (FGR), por medio de uno de sus agentes auxiliares.

Han participado en calidad de amici curiae (amigos del tribunal) la directora de la Fundación Asylum Access Ecuador y el director del Instituto de Derechos Humanos de la Universidad Centroamericana "José Simeón Cañas" (IDHUCA), este último también como apoderado de esa universidad. 


\section{Analizado el proceso y considerando:}

I. 1. A. Los demandantes manifestaron que conforman un grupo familiar de 33 personas divididos en 8 núcleos familiares que, en su mayoría, residian en terrenos vecinos de Delgado, departamento de San Salvador, donde eran acosados por la Mara 18 debido a que 2 miembros de la familia son militares. Relataron que el 15-IV-2016, en horas de la noche, el esposo de la Demandante 1 y otra persona de esa familia fueron interceptados a 2 cuadras de su casa por 3 miembros de dicha pandilla que estaban armados, quienes "los obligaron a desnudarse y los golpearon exigiéndoles que les dijeran quien de sus familiares era soldados", los amenazaron con matarlos y les advirtieron que tenian solamente 24 horas para desalojar su casa, pues de lo contrario la ametrallarían, hechos que afirmaron no haber denunciado por temor a represalias. Posteriormente se registró un segundo ataque a ese grupo familiar el 23-VI-2016, cuando el hijo de la Demandante 1, al salir de la escuela, fue interceptado por un hombre, quien "le dijo que se lo iba a llevar"; sin embargo, el menor gritó y ello, aunado a que habia más personas alrededor, provocó que su agresor se fuera.

Uno de los núcleos familiares está integrado por los Demandantes 5 y 6 , junto a sus 3 hijos menores de edad, quienes fueron victimas de un hecho grave ocurrido la noche del 11X-2016, cuando 4 sujetos —que presumen eran pandilleros-irrumpieron en su vivienda, vestidos de negro y con el rostro cubierto. Estos sujetos sacaron al Demandante 6 de la vivienda para insultarlo, acusarlo de colaborar con la PNC, amenazarlo con matar a su familia y golpearlo de forma reiterada, pero este logró escapar y buscó auxilio en la PNC. Mientras eso ocurría otros dos sujetos insultaron y violaron a la Demandante 5 y a su hija —una niña de 12 años-. Posteriormente amenazaron con matarlas pero no lo hicieron porque un grupo de agentes de la PNC llegó al lugar y los agresores huyeron de la vivienda.

Otro de los demandantes también fue víctima, junto a sus hijos menores de edad, de ataques directos de esos grupos criminales. Durante la noche del 16-X-2016 llegaron a su casa 5 individuos desconocidos que se identificaron como miembros de la Pandilla 18, quienes le manifestaron que ya sabían que tenía 2 hermanos militares y que eso le costaría caro a su familia, pues "la pandilla había ordenado matarlos a todos", a menos que les entregaran la cantidad de \$5.000.00 en una semana; de lo contrario, les pasaría lo mismo que a la familia de los Demandantes 5 y 6.

Estos hechos conminaron a todos los miembros de los 8 núcleos familiares - abuelos, padres e hijos- a desplazarse de sus residencias hacia el Municipio de Berlin, departamento de Usulután.

B. Sin embargo, en ese lugar se vieron obligados a desplazarse nuevamente por motivos de seguridad, en este caso por haber sido victimas de acoso policial y del homicidio de la madre del Demandante 2. Concretamente, señalaron que durante la noche del 17-XII2016, mientras se realizaba un baile cerca de la residencia en la que habitaba parte de la familia, irrumpieron al lugar miembros de la PNC para realizar un cateo, aparentemente en búsqueda de pandilleros. Se produjeron disparos y uno de ellos lesionó a la madre del Demandante 2, quien falleció. Sobre este hecho aseveraron que testigos señalaron 
como responsables a miembros de la PNC. Lo anterior motivó que el grupo familiar se desplazara nuevamente en búsqueda de seguridad.

C. Los peticionarios interpusieron denuncias sobre los hechos descritos en los siguientes términos: (i) con fecha 12-X-2016 los Demandantes 5 y 6 presentaron una denuncia ante la Unidad de Vida e Integridad Física de la Oficina Fiscal de Mejicanos por los hechos del 11-X-2016; (ii) el 17-X-2016 la Demandante 1 y su esposo interpusieron una denuncia ante la División Antiextorsiones de la PNC por los hechos del 16-X-2016; y (iii) con fecha 17-XII-2016 el Demandante 2 denunció y emitió una declaración ante la Subdelegación Policial de Berlín por el homicidio de su madre. Sin embargo, hasta la fecha esos hechos no han sido investigados por las autoridades competentes.

D. Los actores también señalaron que, a pesar del riesgo que existe para su grupo familiar, las autoridades que conocieron de esos hechos en el contexto de las investigaciones de los delitos denunciados se limitaron a asignar claves a las víctimas para evitar que estas fueran identificadas por sus nombres; sin embargo, no solicitaron a su favor —ante la UTE_ medidas extraordinarias de protección, como su incorporación en un albergue para garantizar su seguridad. Por consiguiente, consideran que los jefes de la División Central de Investigaciones, de la División Antiextorsiones, de la Subdelegación Policial de Berlín, todos de la PNC, y el de la Unidad de Vida e Integridad Física de la Oficina Fiscal de Mejicanos vulneraron sus derechos al no activar a su favor las medidas de protección ordinarias y extraordinarias previstas en la LEPVT.

E. Finalmente, sostuvieron que el agravio que les fue causado por las autoridades policiales y fiscales se acentúa —en su calidad de desplazados internos-en virtud de la omisión —que atribuyen, de manera conjunta, al titular del MJSP, a la Asamblea Legislativa, a la Comisión Coordinadora y a la titular de la UTE del Sector de Justicia - de elaborar y promover leyes, normativa reglamentaria, politicas, programas y protocolos de actuación para garantizar la protección de las víctimas de desplazamiento forzado. A su juicio, las referidas autoridades han incumplido el mandato de diseñar e implementar ese tipo de normas y politicas que reconozcan su calidad de desplazados _ junto al resto de personas que se encuentran en iguales condiciones - y les garanticen la asistencia humanitaria y la protección que su condición requiere.

F. Con base en lo expuesto, estimaron vulnerados sus derechos a la seguridad personal, a la protección jurisdiccional y no jurisdiccional, al trabajo, a la salud, a la vivienda y a la libertad de tránsito.

2. A. En la resolución de fecha 6-X-2017 se admitió la demanda, circunscribiéndose al control de constitucionalidad de: (i) la omisión de desarrollar las acciones de protección y seguridad que permitieran la libre circulación hacia y en el entorno de la residencia de los pretensores por parte de los jefes de la División Central de Investigaciones, de la División Antiextorsiones, de la Subdelegación Berlín, todos ellos de la PNC, y de la Unidad de Vida e Integridad Física de la Oficina Fiscal de Mejicanos, por la aparente 
falta de diligencia en la investigación de las denuncias interpuestas por aquellos en virtud de los delitos de los que habian sido objeto; y (ii) contra la presunta omisión de la Asamblea Legislativa, del titular del MJSP, de la Comisión Coordinadora y de la titular de la UTE del Sector de Justicia de emitir, elaborar y promover leyes secundarias, normativa reglamentaria, políticas, programas y protocolos de actuación para garantizar la protección de las víctimas de desplazamiento forzado. Con dichas omisiones se habrían vulnerado los derechos a la seguridad material, a la protección familiar, a la protección jurisdiccional y no jurisdiccional, a la libertad de circulación y a la propiedad de los pretensores.

B. En el referido auto se ordenó la concentración de actos procesales y se adoptó como medida cautelar que las autoridades demandadas competentes debian ordenar las medidas de protección necesarias —entre ellos albergue_ para asegurar la integridad personal y la seguridad de los peticionarios y las medidas pertinentes para judicializar a los responsables de los delitos, asi como proporcionar los mecanismos de seguridad necesarios para que el grupo familiar de los pretensores pudieran retornar a sus residencias a recuperar sus bienes materiales.

Dado que en este proceso el titular de la FGR interviene como miembro de la Comisión Coordinadora del Sector Justicia —una de las autoridades demandadas- y no como un consultor técnico del tribunal, se omitió conceder la audiencia y los traslados que prevén para dicho funcionario los arts. 23, 27 y 30 de la Ley de Procedimientos Constitucionales (L.Pr.Cn.).

3. A. En su intervención, el titular del MJSP negó los hechos atribuidos y sostuvo que entre las funciones que cumple están la prevención de la violencia y el delito, la rehabilitación y reinserción del delincuente, así como las medidas de represión necesarias para contrarrestar las actividades delincuenciales. Asimismo, señaló que en el año 2014 participó en el diseño del "Plan El Salvador Seguro" y actualmente lo hace en su ejecución.

B. El jefe de la División Central de Investigaciones de la PNC sostuvo que los actores no acudieron a dicha institución a denunciar los hechos en cuestión y afirmó que los casos que llegan a su conocimiento se informan a la FGR para recibir direccionamiento fiscal y trabajar en la investigación. Asimismo, señaló que la unidad que dirige aplica las medidas de protección ordinarias y extraordinarias previstas en el art. 10 de la LEPVT.

C. El jefe de la División Antiextorsiones de la PNC negó la vulneración constitucional que se le atribuye y adujo que recibió denuncias de personas a quienes se les asignaron claves para su identificación conforme a la LEPVT, las cuales fueron enviadas a la FGR y se realizaron diversas acciones como operativos y detenciones de sospechosos, por lo que dicha institución tomó acciones encaminadas a proteger los derechos de las víctimas y, por tal razón, solicitó el sobreseimiento del presente proceso.

D. El jefe de la Subdelegación de Berlín de la PNC indicó que no se tenían registros en la base de datos informáticos y físicos que lleva dicha subdelegación sobre denuncias relacionadas a los casos señalados por los pretensores, razón por la cual no se hizo uso 
de la herramienta legal establecida en la LEPVT; sin embargo, planteó una versión de los hechos ocurridos en ese municipio que difiere de la expuesta por los actores. Señaló que sus actuaciones son apegadas a Derecho y solicitó que se sobreseyera el presente amparo.

E. La Asamblea Legislativa negó los hechos atribuidos y sostuvo que, si bien no existe legislación específica sobre desplazamiento forzado, ha emitido normativa para proteger a las víctimas por medio de la LEPVT, por lo que no existe la omisión alegada por los actores $y$, por ello, solicitó se declarara que no ha lugar el amparo requerido por estos. F. La Comisión Coordinadora y la titular de la UTE del Sector de Justicia sostuvieron que no conculcaron los derechos de los actores, pues han trabajado para fortalecer el programa de protección a víctimas y testigos, el cual es aplicable sin discriminación a todas las víctimas, por lo que solicitó el sobreseimiento del proceso y la revocatoria de la medida cautelar ordenada por este Tribunal.

G. El Director de la PNC también intervino en este proceso, reiterando lo señalado por los jefes de las divisiones específicas de esa institución y la petición de sobreseimiento. H. La jefa de la Unidad de Vida e Integridad Física de la Oficina Fiscal de Mejicanos no rindió oportunamente el informe que le fue requerido. Dicha autoridad intervino hasta la audiencia probatoria, en la cual señaló que carecía de legitimación pasiva porque la investigación de los hechos denunciados por los Demandantes 5 y 6 y su hija fue asignada a la Unidad de Delitos Relativos a la Niñez, Adolescencia y Mujer en su Relación Familiar.

4. Mediante resolución de fecha 5-III-2018 se declararon sin lugar los sobreseimientos solicitados por las autoridades demandadas y la revocatoria de la medida cautelar, la cual fue confirmada. Asimismo, se abrió a pruebas el presente proceso, plazo en el cual las partes propusieron prueba documental, de almacenamiento de información y de declaración de propia parte del Demandante 2.

5. A. En virtud de la resolución de fecha 16-V-2018 se admitió la prueba propuesta por las partes y se señaló día y hora para la audiencia en la que se produciría la declaración de propia parte del Demandante 2 y los alegatos finales de todas las partes.

B. Con fecha 8-VI-2018 se suspendió la audiencia programada debido a la incomparecencia de 2 de las autoridades demandadas y se reprogramó para el 13-VI-2018, fecha en la que se llevó a cabo y en ella se produjo la declaración de propia parte del Demandante 2 y los alegatos finales de todos los intervinientes, quienes, en esencia, reiteraron los argumentos expuestos en sus intervenciones previas.

6. Posteriormente se recibieron escritos firmados por los apoderados de la Asamblea Legislativa y de la PNC, en los que solicitaron la entrega de copias de las actas y audio de la audiencia de prueba y del acta de su suspensión previa. Asimismo, en la audiencia probatoria el apoderado de la Comisión Coordinadora del Sector de Justicia y de la UTE requirió que se le entregara una copia del soporte audiovisual de dicha audiencia. 
II. El orden con el que se estructurará esta resolución es el siguiente: en primer lugar, se determinará el objeto de la controversia (III); en segundo lugar, se hará una breve exposición sobre las funciones del Estado, el contenido de los derechos fundamentales que se arguyen vulnerados y la idoneidad del proceso de amparo para tutelar derechos de personas y colectivos en situación de vulnerabilidad (IV); en tercer lugar, se desarrollarán algunas nociones generales sobre el fenómeno migratorio y el desplazamiento forzado, el contexto en el que se enmarcan los hechos alegados y las obligaciones que la Constitución y el Derecho Internacional imponen al Estado frente a las víctimas de desplazamiento forzado (v); en cuarto lugar, sobre la base de los argumentos de las partes, la prueba aportada al proceso y las consideraciones jurídicas y fácticas realizadas por este Tribunal, se analizará el caso sometido a conocimiento (VI); y finalmente, se determinará el efecto del fallo (VII).

III. 1. A. En la Sentencia de fecha 4-I-1994, Amp. 4-M-93, se afirmó que la protección que el amparo brinda a los derechos fundamentales impide desconocer que distintos sujetos o agrupaciones de naturaleza privada son capaces de oponerse al poder del Estado y de amenazar o atacar al individuo en sus derechos fundamentales.

El proceso de amparo no es, por regla general —salvo los supuestos excepcionales señalados en la Sentencia de fecha 4-III-2011, Amp. 934-2007-, el mecanismo inmediato al que deben acudir las personas para requerir la tutela de sus derechos fundamentales cuando estos les han sido vulnerados por otros particulares, ya que, en principio, deben requerir la protección de la jurisdicción ordinaria o de las autoridades no jurisdiccionales mediante la aplicación de la ley. De ahi que este Tribunal se encuentre facultado para controlar actos -y en algunos supuestos omisiones - de autoridades públicas cuando estas han brindado una protección deficiente o nula a los derechos fundamentales en esos supuestos (Sentencia de fecha 13-XII-2017, Amp. 532-2015).

$B$. Al respecto, los peticionarios narraron en su demanda algunos hechos de gravedad que atribuyen directamente al accionar de las pandillas y relataron que algunos miembros de su grupo familiar fueron victimas directas de amenazas, lesiones, extorsiones y violaciones sexuales que los conminaron a desplazarse desde sus residencias a otro sitio en búsqueda de protección. En este segundo lugar - municipio de Berlin- tampoco encontraron las condiciones de seguridad que esperaban, en virtud del acoso policial al que fueron sometidos y al homicidio de la madre de uno de los demandantes. Actualmente la mayoría de ellos, a excepción del que declaró en la audiencia probatoria, se encuentran fuera del país, pues la situación de violencia e inseguridad les impide retornar a sus hogares y temen ser víctimas de hechos similares a los que ya sufrieron. Los actores reclaman contra dos tipos de omisiones que consideran han vulnerado sus derechos fundamentales: (i) la primera atribuida a autoridades policiales y fiscales, en virtud de no haber desarrollado investigaciones exhaustivas y concluyentes sobre los hechos que denunciaron; y (ii) la segunda de indole legislativa y creación e implementación de políticas públicas que, si bien constituye un tema abstracto, les causa un agravio directo y concreto, pues tienen de facto la calidad de desplazados, aun cuando el Estado no reconoce la magnitud del fenómeno de desplazamiento forzado a raíz de la 
violencia. Estas vulneraciones se mantienen hasta la fecha —es decir, se trata de una vulneración continuada de derechos fundamentales_, pues la situación de inseguridad no les permite garantizar el retorno a sus residencias.

C. En definitiva, los hechos del caso se refieren a graves afectaciones a derechos fundamentales que, en principio, fueron causadas directamente por grupos delictivos -y, por consiguiente, estos hechos entran en el ámbito de conocimiento y aplicación de la legislación penal y procesal penal_, pero los actores atribuyen a las autoridades demandadas vulneraciones a sus derechos en virtud de las omisiones de investigar los hechos denunciados, de brindarles protección frente a los grupos de sujetos que conforman estructuras criminales ampliamente reconocidas por las instituciones del Estado y, sobre todo, de crear los mecanismos necesarios para brindar dicha protección de forma generalizada y sistemática a las personas que son víctimas de desplazamiento forzado.

2. Acotado lo anterior, el objeto de la controversia puesta en conocimiento de este Tribunal consiste en determinar: (i) por una parte, si la omisión atribuida a los jefes de la División Central de Investigaciones, de la División Antiextorsiones, de la Subdelegación de Berlín, todos de la PNC, y de la Unidad de Vida e Integridad Física de la Oficina Fiscal de Mejicanos, de investigar las denuncias efectuadas en fechas 12-X-2016, 17-X-2016 y 17XII-2016 por algunos de los actores en relación con los hechos acontecidos el 11-X-2016, el 16-X-2016 y la muerte de la madre del Demandante 2, respectivamente, asi como de ordenar las medidas de protección necesarias a favor de los pretensores que les permitieran circular libremente hacia y en el entorno de sus residencias, vulneró los derechos fundamentales a la seguridad material, a la protección de la familia, a la protección jurisdiccional y no jurisdiccional, a las libertades de circulación y de residencia, y a la propiedad de los demandantes; y (ii) por otra parte, si la omisión del titular del MJSP, de la Asamblea Legislativa, de la Comisión Coordinadora y de la titular de la UTE del Sector de Justicia de emitir, elaborar y promover leyes secundarias, normativa reglamentaria, politicas, programas y protocolos de actuación para garantizar la protección de las víctimas de desplazamiento forzado interno, vulneró los referidos derechos fundamentales de los pretensores y del resto de personas que se encuentran en igualdad de condiciones como víctimas de desplazamiento forzado.

IV. 1. A. La convivencia pacífica es una aspiración legítima de todo cuerpo social. Sin embargo la vida en sociedad se caracteriza por las tensiones y las confrontaciones de los individuos y los grupos que la conforman. El conflicto y la violencia son rasgos que yacen bajo las relaciones sociales y que al emerger sin ningún tipo de control externo pueden desintegrar el tejido social y poner en serio riesgo la libre y pacifica coexistencia de personas y grupos sociales, en particular de aquellos que ocupan por diversas razones posiciones subordinadas en la estructura social, es decir los más débiles. En consecuencia, los ordenamientos jurídicos prevén como ilícitos determinados comportamientos antisociales y prescriben sus correspondientes sanciones que son impuestas por los Estados mediante la coacción, con el fin de asegurar la convivencia en un espacio determinado. En efecto, los Estados despliegan los ordenamientos dentro de sus 
territorios y sobre la población radicada en ellos. En estos ámbitos de validez espacial y personal los Estados proscriben el uso ilegítimo de la violencia física y al mismo tiempo reclaman para sí mismos el ejercicio exclusivo del poder de coacción, que es un elemento constitutivo de la soberanía. Desde el punto de vista interno, la soberanía presupone que el Estado cuente con el monopolio de la coacción y que lo ejerza en la totalidad de su territorio sin que existan zonas que se resistan o se exceptúen de su aplicación. Resulta evidente que sin poderes públicos que ordenen las relaciones humanas y eviten la coacción irracional la vida en sociedad sería caótica y, por tanto, inicua; sometido el cuerpo social a los individuos o a los grupos más fuertes, la vida no podría transcurrir en paz y en relativo orden. De ahi que el monopolio y uso racional de la violencia física, conforme las reglas y los valores previstos en el ordenamiento jurídico, son una función básica del Estado.

B. Sin embargo, conseguir la obediencia al ordenamiento por medio de la coacción no es la única función del Estado, ni mucho menos puede afirmarse que esta sea su razón de ser en las sociedades contemporáneas. Si acaso lo fue en los orígenes de los Estados nacionales en Occidente, al cabo de un largo proceso histórico, en las actuales circunstancias no podría predicarse lo mismo. Es cierto que la aplicación de la violencia legitima constituye un instrumento para garantizar la convivencia pacífica, pero también es verdad que existen otros medios que hacen posible la coexistencia de las personas en libertad y en paz. La aceptación de las reglas y los valores del ordenamiento jurídico no se logra solo con la amenaza de la coacción o con su efectiva aplicación ante los actos ilícitos. Asumir que esta sea la principal función del Estado implicaría asignarle el papel de un gendarme encargado de la seguridad de la población y de sus pertenencias. En las actuales sociedades caracterizadas por el pluralismo el Estado tiene sin duda un papel más complejo que llevar a cabo. La convivencia pacífica no depende solo de la seguridad física de los individuos y de la protección de sus bienes, sino de la existencia de equilibrios entre las capas sociales. La marginación de amplios sectores de la población vuelve difícil la coexistencia y la experiencia indica que da lugar a conflictos al interior de la sociedad. En estos contextos los derechos fundamentales de contenido social emergen como instrumentos que procuran la integración de los sectores marginados y exigen en consecuencia una intervención del Estado en el funcionamiento de la sociedad.

Desde el punto de vista de los derechos fundamentales, la marginación social pone de manifiesto que existe en la sociedad una desigual satisfacción de los derechos sociales y que la tutela de estos derechos es deficiente. La tarea de garantizar los derechos sociales no es exclusiva del órgano jurisdiccional, sino que involucra a diversas instituciones del Estado, desde las encargadas de formular y ejecutar las políticas sociales y de prestar los servicios públicos esenciales hasta el cuerpo legislativo, que configura legalmente estos derechos. Por consiguiente, la convivencia en paz en una sociedad plural es también resultado de la efectividad de los derechos fundamentales de indole social reconocidos en un ordenamiento y que encarnan valores como el bien común y la igualdad.

C. De acuerdo con la Constitución el Estado reconoce a la persona humana como el origen y el fin de su actividad y se organiza para alcanzar la justicia, la seguridad jurídica 
y el bien común. Sin embargo, la persona humana no es un individuo que vive aislado sino en una sociedad integrada por otras personas, con quienes convive. Su relación con la sociedad es regulada por el ordenamiento jurídico y la función del Estado salvadoreño es garantizar la convivencia pacífica del individuo en una determinada sociedad. Así se explica que la Constitución prescriba que el Estado se organizará para conseguir la justicia, la seguridad jurídica y el bien común, porque estos son fines que suponen la satisfacción tanto de los derechos civiles y políticos como de los derechos sociales.

2. A. En la Sentencia de fecha 5-II-2014, Amp. 665-2010, se afirmó que de la dimensión objetiva de los derechos fundamentales se configura el deber genérico de protección de estos. Asi, del significado y funciones de estos derechos dentro del orden constitucional, se desprende que la garantía de su vigencia no puede limitarse a la posibilidad del ejercicio de pretensiones por parte de los individuos, sino que ha de ser asumida por el Estado. Por consiguiente, este tiene tanto la prohibición de lesionar la esfera individual protegida por los derechos fundamentales como la obligación de contribuir a la efectividad de tales derechos. En efecto, según ha sido caracterizada por la jurisprudencia constitucional, la justicia, como concepto omnicomprensivo, exige garantizar a todos los individuos una cuota igual de libertad (Sentencia de fecha 23-III-2001, Inc. 8-97). En ese sentido, los derechos fundamentales vinculan a todos los poderes públicos y son la fuente de obligaciones para el Estado, principalmente en las tareas de prevención, promoción, protección y reparación de los daños ocasionados.

Este deber de protección que el Estado tiene frente a los particulares opera también respecto de las intromisiones ilegítimas a sus derechos fundamentales por otros particulares y se verifica mediante la interpretación y aplicación de la ley para resolver conflictos de derechos (Sentencia de fecha 24-IX-2010, Inc. 91-2007), pero su contenido va más allá de las decisiones judiciales. En efecto, en la Sentencia de fecha 12-XI-2010, Inc. 40-2009, se afirmó que el art. 2 de la Cn. consagra el derecho a la protección en la conservación y defensa de los derechos reconocidos en favor de toda persona, el cual es correlativo al aludido deber de protección.

B. La conservación de los derechos que reconoce la Constitución es, en efecto, una forma de protección que implica el establecimiento de acciones o mecanismos para evitar que los derechos constitucionales sean vulnerados, limitados o, en última instancia, extraídos inconstitucionalmente de la esfera jurídica de cada persona. Esta primera modalidad de protección incorpora un derecho a que el Estado impida razonablemente las posibles vulneraciones a los demás derechos materiales. Esta conservación no solo se logra mediante la vía jurisdiccional, sino también por medio de vías administrativas o "no jurisdiccionales", como las acciones estatales "previsionales" encaminadas a evitar o prevenir posibles infracciones a derechos constitucionales (Sentencia de Inc. 40-2009).

Asi, por ejemplo, en el contexto de violencia estructural que afecte a un amplio sector del territorio, estas medidas deben estar enfocadas en la prevención del delito y de afectaciones a derechos como la seguridad material, la integridad física, la libertad de circulación, la libertad de residencia, propiedad privada y la protección de la familia 
particularmente a las mujeres y la niñez, provenientes de sujetos que se arrogan competencias propias del Estado, como el control del territorio.

C. El derecho a la protección en la defensa jurisdiccional de los derechos conlleva, entre otras cosas, la posibilidad de que el supuesto titular de un derecho o de un interés legítimos pueda acceder al órgano jurisdiccional a plantear sus pretensiones -en todos los grados y niveles procesales-, a oponerse a las ya incoadas por otras personas, a ejercer todos los actos procesales en defensa de su posición $y$, finalmente, a que el proceso se tramite y decida de conformidad a la Constitución y a las leyes correspondientes obteniendo una respuesta fundada en el Derecho.

Lo anterior es predicable también del derecho a la protección en la defensa no jurisdiccional, pues tanto los jueces y magistrados, al ejercer la potestad de juzgar y hacer ejecutar lo juzgado que les encomienda el art. 172 de la Cn., como las autoridades no jurisdiccionales, al resolver los casos concretos que son sometidos a su conocimiento mediante la aplicación del Derecho, tienen el deber de resolver de manera motivada y congruente a lo pedido por las partes dentro de un determinado proceso o procedimiento.

3. Este tribunal ha señalado que el derecho a la seguridad (art. 2 inc. $1^{\circ}$ de la Cn.) tiene dos dimensiones: como seguridad material y como seguridad jurídica. En su primera dimensión equivale a un derecho a la tranquilidad de poder disfrutar sin riesgos, sobresaltos ni temores los bienes muebles o inmuebles que cada uno posee, o de que el Estado tomará las medidas pertinentes y preventivas para no sufrir ningún daño o perturbación en la persona (Sentencia de fecha 7-IX-2001, Inc. 15-98). Ese criterio fue retomado en la Sentencia de fecha 26-VIII-2011, Amp. 253-2009, en la cual se afirmó que el derecho a la seguridad material implica el derecho de estar libre o exento de todo peligro, daño o riesgo que ilegítimamente amenace los derechos.

Posteriormente, en la Sentencia de fecha 28-IV-2015, Amp. 787-2012, se sostuvo que el derecho a la seguridad material posee dos facetas: una colectiva y otra individual. La primera se refiere al derecho de los miembros de la sociedad en su conjunto a ser protegidos frente a aquellas circunstancias que ponen en riesgo bienes jurídicos colectivos importantes, como por ejemplo el patrimonio público, el espacio público, la salud y el medio ambiente. La segunda, en cambio, está referida al derecho de las personas de recibir protección adecuada de las autoridades cuando estén expuestas a riesgos excepcionales que no tienen el deber jurídico de tolerar, por rebasar estos los niveles soportables de peligro implícitos en la vida en sociedad.

Para que las prestaciones necesarias en cada situación concreta sean exigibles al Estado, es preciso probar los hechos que apuntan a la existencia de un riesgo extraordinario o extremo. Así, será necesario demostrar: (i) que el riesgo respecto del cual se pide protección ante las autoridades administrativas o judiciales competentes reúne todas o la mayoría de las características antes apuntadas; y (ii) la situación de vulnerabilidad o especial exposición al riesgo en que se encuentran la persona o el colectivo afectados.

4. A. En la Sentencia de fecha 20-IX-2017, Amp. 623-2015, se indicó que el derecho a la protección familiar es aquel en virtud del cual el Estado debe asegurar a todas las personas 
el disfrute de una convivencia digna con su núcleo familiar, independientemente de la forma que este adopte, y eliminar toda forma de obstrucción arbitraria a este derecho por parte de cualquier entidad pública o privada. Dicho derecho se encuentra reconocido en el art. 32 inc. $1^{\circ}$ de la Cn., el cual establece que la familia es la base fundamental de la sociedad y tendrá la protección del Estado, imponiendo a este último la obligación de dictar la legislación necesaria y crear los organismos y servicios apropiados para su integración, bienestar y desarrollo social, cultural y económico.

La obligación del Estado de proteger a la familia proviene de la fundamentalidad que la Constitución le reconoce a dicha institución. Ese carácter fundamental tiene su origen en la composición de la familia, en el sentido de que, si la persona humana es el origen y el fin de la actividad del estado (art. 1 inc. $1^{\circ}$ de la Cn.), entonces una agrupación de personas unidas por rasgos biológicos y afectivos que se establecen de forma permanente en una sociedad merece una especial protección.

B. Además de la función natural de la familia -la procreación-, se identifica en esta otras dos funciones: (i) una moral o afectiva, que implica el establecimiento de lazos sentimentales entre sus miembros de modo que se crea una identidad de pertenencia, conservación y apoyo recíproco; y (ii) una económica o de subsistencia, consistente en el aseguramiento por parte del grupo familiar de los elementos básicos -vivienda y alimento-para asegurar su permanencia y estabilidad.

Es por las funciones sociales y jurídicas que cumple la familia dentro de la sociedad que requiere de una protección reforzada del Estado, mediante instrumentos jurídicos, políticas públicas y, en general, de su propio actuar. Lo anterior implica, por una parte, un deber de abstención o de no injerencia del Estado y, por otro, la existencia de obligaciones positivas o prestacionales de realizar todo lo que se encuentre al alcance de este para fomentar la protección familiar y la conservación de la familia como base fundamental de la sociedad.

6. A. En las Sentencias de fechas 5-IV-2005 y 25-IX-2013, Amps. 107-2009 y 5452010, se caracterizó el derecho a la libertad de circulación (art. 5 de la Cn.) como la facultad de toda persona de moverse libremente en el espacio, sin más limitaciones que aquellas impuestas por las condiciones del medio en el que pretende actuar. Por ello, las notas características de este derecho son la acción de movilizarse del sujeto, el ámbito físico en el que pretende desplazarse y la inexistencia de obstáculos que dificulten su tránsito de un sitio a otro.

Así, se estará en presencia de una vulneración del derecho a la libertad de circulación cuando se dificulte o impida de manera injustificada a una persona el libre desplazamiento de un sitio a otro. En estos supuestos, a diferencia de los que se deben tipificar como vulneraciones del derecho a la libertad personal, no ocurre una reclusión, encierro o apartamiento físico del individuo.

B. Asimismo, la libertad de elegir residencia y domicilio y de permanecer en el que sea elegido es otra manifestación que se desprende del contenido del art. 5 inc. $2^{\circ}$ de la Cn. De acuerdo con esta facultad las personas pueden escoger su residencia y su domicilio, cambiarlos cuando así lo decidan y mantenerlos si fuese esa su voluntad. 
En consecuencia, ninguna persona puede ser obligada a elegir donde establecerse ni a abandonar el lugar que fijen como su residencia, excepto por mandato judicial en los supuestos previstos en la ley.

$Y$ es que el arraigo en un espacio geográfico determinado obedece a una necesidad de indole antropológica, que obliga a las personas a establecer un punto fijo en sus vidas cotidianas que les ofrezca seguridad frente a la intemperie y que consideren su hogar. Ese punto fijo en las vidas de las personas es la residencia y por la importancia que reviste para el desarrollo de los proyectos de vida de estas el ordenamiento jurídico le otorga una protección especial mediante el reconocimiento del referido derecho fundamental.

7. El derecho a la propiedad (art. 2 inc. $1^{\circ}$ de la Cn.) faculta a una persona a: (i) usar libremente los bienes, que implica la potestad del propietario de servirse de la cosa y aprovechar los servicios que rinda; (ii) gozar libremente de los bienes, que se manifiesta en la posibilidad del dueño de recoger todos los productos que deriven de su explotación, y (iii) disponer libremente de los bienes, que se traduce en actos de enajenación respecto a la titularidad del bien.

En suma, las modalidades del derecho de propiedad, esto es, el libre uso, goce y disposición de los bienes, se ejercen sin otras limitaciones más que aquellas establecidas en la Constitución o la ley. Así, la propiedad se encuentra limitada por el objeto natural al cual se debe: la función social.

8. A. El amparo ha sufrido importantes transformaciones desde su incorporación en la Constitución de 1886. La Ley de Amparos de 1950 y, posteriormente, la Ley de Procedimientos Constitucionales de 1960 delimitaron sus supuestos de procedencia y fijaron las reglas sobre el trámite de dicho proceso. Sin embargo, desde entonces las principales innovaciones han sido producto de los aportes jurisprudenciales de este Tribunal a partir de la interpretación de la Constitución y de su autonomía procesal. Como se ha afirmado en reiterada jurisprudencia, no se trata de aplicar la Constitución en función de las normas procedimentales, sino de darle a estas un contenido propio conforme a aquella. En definitiva, se trata de garantizar la idoneidad del proceso para la tutela efectiva de los derechos fundamentales conforme a lo dispuesto en el art. 247 de la Cn.

B. El amparo es un mecanismo procesal idóneo para tutelar derechos de personas o grupos de personas en condición de vulnerabilidad. Ello ha permitido a esta Sala conocer sobre supuestos de vulneraciones a derechos de personas con VIH - Sentencias de fechas 21-IX-2011 y 11-III-2015, Amps. 166-2009 y 749-2014-, adultos mayores e indigentes —Sentencia de fecha 22-XII-2017, Amp. 370-2015-, pacientes de hemofilia - Sentencia de fecha 25-IX-2017, Amp. 938-2014-y de insuficiencia renal -Sentencia de fecha 2VII-2018, Amp. 701-2016_, entre otros. De ahí que, en el presente caso, se debe también tomar en cuenta la situación de vulnerabilidad en la que se encuentran los desplazados internos por el fenómeno de la violencia. 
C. De igual forma, las dimensiones subjetiva y objetiva del amparo también han justificado de manera excepcional el control de omisiones de políticas públicas, cuando estas favorecen la continuidad de afectaciones graves y prolongadas de derechos fundamentales de personas en condición de vulnerabilidad. Ese es el caso de la Sentencia de fecha 25-IX-2017, Amp. 938-2014, con relación a la falta de tratamiento de salud adecuado en el sistema público de salud para las personas que padecen de hemofilia.

V. 1. A. La migración es un fenómeno multicausal que ha acompañado a la humanidad en su devenir histórico. La escasez de recursos naturales, la búsqueda de oportunidades de mejora económica y la reunificación familiar han sido, entre muchos otros, factores que históricamente han motivado al ser humano a migrar. En relación con el objeto de este proceso, es necesario distinguir entre dos tipos de migración: (i) en atención al elemento volitivo, la migración es voluntaria o forzada; $y$ (ii) en razón del ámbito geográfico, la que se produce en el ámbito interno del Estado y la internacional.

En atención al elemento volitivo, la complejidad del fenómeno impide categorizar de manera cerrada los flujos migratorios, en especial cuando, si bien existe el ánimo de migrar, este también puede estar motivado por factores externos al sujeto. No obstante, es posible identificar en este tipo de migración ciertas situaciones claras:

a. La migración voluntaria, independientemente de si se produce en el ámbito interno o en el internacional, se caracteriza porque el migrante actúa motivado por el ánimo de trasladar su residencia - temporalmente o de manera definitiva-del lugar en el que se ha asentado durante su vida o durante un lapso prolongado de tiempo a otro en el que pretende establecerse, con el pleno conocimiento de los efectos de su decisión en las distintas áreas de su vida —familiar, social, laboral, etc.-.

b. La migración forzada, que se caracteriza por el abandono del lugar de residencia, propiedades y círculo familiar -en sentido extenso-y social inmediato en busca de seguridad y protección, cuando estas no pueden ser garantizadas en el entorno espacial inmediato. Se trata de un fenómeno complejo que tiene origen en causas de gravedad notoria que conminan a la persona a abandonar su lugar de residencia, incluso de manera abrupta, por el temor de sufrir daños irreversibles.

En este tipo de migración se distingue entre dos figuras que, aun cuando no son las únicas manifestaciones del fenómeno, requieren de un tratamiento especial debido a la gravedad de sus causas y a su impacto en la vida del migrante: (i) el desplazamiento interno o forzado, que consiste en un tipo de movilidad humana generalmente masiva - progresiva o dispersa - que se produce por motivos de gran complejidad que conminan a las personas a abandonar sus lugares de residencia por otros donde puedan encontrar mejores condiciones de seguridad y protección, pero sin cruzar los limites fronterizos de ese Estado; y (ii) el refugio, que ocurre cuando una persona es perseguida en su país de origen, entre otros, por motivos ideológicos, religiosos, raciales y culturales y lo abandona para llegar a otro en el que pueda resguardar su vida, integridad y seguridad. 
B. Los Principios Rectores de los Desplazamientos Internos de la Organización de las Naciones Unidas (ONU) cataloga como desplazados internos a "las personas o grupos de personas que se han visto forzadas u obligadas a escapar o huir de su hogar o de su lugar de residencia habitual, en particular como resultado o para evitar los efectos de un conflicto armado, de situaciones de violencia generalizada, de violaciones de los derechos humanos o de catástrofes naturales o provocadas por el ser humano, y que no han cruzado una frontera estatal internacionalmente reconocida" —itálicas suplidas-. Algunas concepciones tradicionales del fenómeno lo han ubicado en el contexto de los conflictos armados, pues estos dan lugar a la movilidad masiva de personas en busca de seguridad y de protección. Sin embargo, el Derecho Internacional, así como la doctrina y la jurisprudencia internacional y comparada, han sido enfáticos en señalar que las causas del desplazamiento forzado son múltiples, entre ellas: (i) desastres naturales; (ii) situaciones de violencia generalizada que producen un grave riesgo para la vida y la integridad de las personas que viven en comunidades afectadas por enfrentamientos armados o que están sometidas al control territorial de grupos al margen de la ley; y (iii) proyectos de desarrollo de amplio alcance como los que tienen lugar en el ámbito de las industrias extractivas, que pueden dar lugar al desplazamiento de poblaciones particularmente vulnerables -v. gr., comunidades indigenas u otros colectivos que se caracterizan por su dependencia y vinculación material y espiritual con la tierra-. En general, las causas del desplazamiento forzado son de gran complejidad y su erradicación escapa de la voluntad y de la capacidad del sujeto afectado, por lo que enfrentar dicho fenómeno requiere de medidas de protección y reparación complejas, de amplio alcance. Por consiguiente, la asistencia y la protección a las víctimas de desplazamiento forzado no deben ser abordadas de manera aislada, sino integral, tomando en cuenta el contexto mismo que afecta a otros sujetos en situaciones similares.

2. A. a. En el caso concreto, los pretensores afirman ser víctimas de un fenómeno de desplazamiento forzado a causa de la violencia e inseguridad generadas por grupos al margen de la ley. Los actores se refieren a dicho fenómeno como una situación de violencia sistemática que afecta a grupos de personas vulnerables debido a sus condiciones socioeconómicas, la cual es atribuible a las pandillas, pero también al Estado por la inobservancia de su deber de protección de la población afectada. Inclusive, señalan la negativa de las autoridades de reconocer el desplazamiento interno como una situación que afecta a un alto porcentaje de la población y de ubicarlo en el contexto de la violencia estructural y sistemática que tiene lugar en distintos sectores del territorio.

b. Los amici curiae, citando las Directrices de elegibilidad para la evaluación de las necesidades de protección internacional de los solicitantes de asilo procedentes de El Salvador del Alto Comisionado de las Naciones Unidas para los Refugiados (ACNUR), indican que El Salvador tiene la mayor concentración de miembros de pandilla de la región.

Estos grupos delincuenciales son, a su juicio, "la principal fuerza que ha impulsado el aumento de la violencia en El Salvador durante la última década y el aumento de homicidios y desplazamientos de la población en el último par de años" —itálicas suplidas-. 
Agregaron que el Estado cuenta con un instrumento que desarrolla la política en materia de seguridad _Plan El Salvador Seguro_- pero ha omitido reconocer de manera oficial el fenómeno del desplazamiento forzado a raíz de las pandillas, a excepción de la Procuraduría para la Defensa de los Derechos Humanos (PDDH), que si lo ha reconocido de manera categórica.

Indicaron que los medios de intimidación utilizados por las pandillas y otros grupos de crimen organizado en contra de la población civil consisten en amenazas y agresiones "progresivamente más y más graves, de modo que las víctimas de desplazamiento forzado normalmente ya han sufrido una serie de amenazas y agresiones en aumento, cuando finalmente se ven forzados a huir en anticipación de agresiones más graves". Agregaron que, si bien El Salvador no atraviesa un conflicto armado, le son aplicables las normas internacionales -entre ellas, los principios rectores antes citados-que reconocen derechos a favor de los desplazados, por encontrarse en una situación de violencia generalizada, esto es, un fenómeno de violencia indiscriminada capaz de afectar a grupos de personas o a poblaciones enteras.

B. En anteriores oportunidades - v. gr., en las Sentencias de fechas 23-I-2017, HC 145-2015, y 13-VII-2016, Inc. 44-2013- este Tribunal se ha referido a la utilidad del análisis de contexto en los casos de vulneraciones sistemáticas a derechos fundamentales. También, algunos tribunales internacionales como la Corte Interamericana de Derechos Humanos (Corte IDH) y la Corte Penal Internacional (Caso del Fiscal C. Germain Katanga) han acudido, en supuestos de especial complejidad, al contexto.

En el presente caso, tanto los demandantes como los amici curiae describieron el contexto en el que se enmarcan los hechos alegados por los primeros y las autoridades demandadas han tenido la oportunidad de controvertir esas afirmaciones; con lo cual se cumplen los presupuestos para analizar los hechos planteados en la demanda a la luz del contexto alegado. En consecuencia, se debe determinar si los hechos narrados por los actores se insertan en la situación de violencia estructural y sistemática que han descrito.

a. Al respecto, ante este Tribunal se han presentado cuatro demandas de amparo, actualmente en trámite, en las que se alegan hechos similares a los del presente proceso. Asimismo, en la Sentencia de fecha 24-VIII-2015, Inc. 22-2007, se estableció que las organizaciones criminales antes mencionadas realizan de manera sistemática, planificada y organizada, entre otros: (i) atentados sistemáticos a la vida, seguridad e integridad de la población y de las autoridades civiles, militares, policiales y penitenciarias; (ii) menoscabos a la propiedad mediante la ejecución de delitos de extorsión a personas naturales y jurídicas; (iii) vulneraciones del derecho a residir en cualquier lugar del territorio, obligando a las personas a abandonar sus residencias mediante amenazas; (iv) vulneraciones del derecho a la educación al provocar la deserción de estudiantes debido al temor a ser víctima de aquellas organizaciones; (v) atentados al libre tránsito en la medida en que hay zonas especificas donde ciertas personas no pueden circular por el riesgo de sufrir atentados a su vida o integridad; (vi) modificaciones a la distribución territorial establecida por el Tribunal Supremo Electoral para el voto residencial; (vii) paralización del transporte público de pasajeros y atentados a la vida del personal 
de los servicios de transporte público; y (viii) obstaculización de las actividades económicas y laborales de amplios sectores de la población.

b. En las Memorias del XXX Aniversario de la Declaración de Cartagena sobre los Refugiados, publicadas por el ACNUR en 2015, se señaló que "la región se enfrenta a situaciones nuevas que están teniendo un impacto humanitario en la población y que, en algunos casos, conducen al desplazamiento forzado. En el Triángulo Norte de Centroamérica [...] los actos del crimen organizado transnacional están provocando el desplazamiento forzado de ciudadanos de estos países, afectando especialmente a las mujeres, adolescentes y menores no acompañados".

En ese mismo documento se indicó que el Triángulo Norte de Centroamérica "cuenta con uno de los indices más altos de violencia del mundo a causa de las acciones del crimen organizado transnacional. Aunque el impacto más visible de la violencia es la tasa de homicidios, hay otros indicadores que demuestran las graves consecuencias humanitarias como el número de heridos, el reclutamiento y asesinato de niños, niñas y adolescentes, la extorsión, los secuestros, los problemas de acceso a la salud y a la educación, la creciente violencia sexual y por motivos de género, así como el alto costo social y económico y el desplazamiento forzado de personas tanto al interior de los países como transfronterizo" -itálicas suplidas-.

En el apartado "Nuevas tendencias de desplazamiento forzado en Mesoamérica" de las citadas memorias (párr. 10), se indicó que a finales de 2013 se registraron más de 18.500 refugiados provenientes del Triángulo Norte de Centroamérica, que las solicitudes de refugio se incrementaron considerablemente de 2009 a 2013 y que la segunda causa de la migración de esas personas era la violencia.

Además, en su informe de 2016 _publicado en 2017- sobre las tendencias globales del desplazamiento forzado, entre otras cuestiones, el ACNUR señaló que: (i) las solicitudes de asilo de salvadoreños "casi se duplicaron, de 18.900 el año anterior a 33.600 en 2016, por lo que El Salvador pasó a ser el primer país de origen" de solicitantes de asilo en los Estados Unidos de América, pero a nivel global las solicitudes de asilo de salvadoreños habian llegado a 42.900; y (ii) la cantidad de refugiados salvadoreños en otros países también era alarmante, con un número aproximado de 19.614, de los cuales 1.181 eran atendidos por el ACNUR, y un total de solicitudes de asilo pendientes de 62.167.

En definitiva, ambos informes coinciden en que, además del desplazamiento interno a causa de la violencia, se está experimentando un fenómeno de migración internacional que se refleja en el considerable aumento de las solicitudes de refugio y de asilo de salvadoreños a otros Estados.

c. Sobre el fenómeno del desplazamiento forzado en El Salvador, la Relatora Especial sobre los derechos humanos de los desplazados internos de Naciones Unidas, en el informe sobre su visita a El Salvador en 2017 que presentó ante el Consejo de Derechos Humanos de ese organismo en su $38^{\circ}$ período de sesiones, destacó que: (i) las autoridades públicas son renuentes a reconocer el fenómeno de desplazamiento interno, pues consideran que el contexto actual es distinto al que originó el desplazamiento masivo de personas durante el conflicto armado; (ii) existe una marcada disparidad 
entre las estadísticas de desplazados que manejan algunas instituciones estatales y las publicadas por distintas organizaciones privadas nacionales e internacionales, que reflejan una tasa considerablemente alta de desplazados internos; (iii) en el año 2016 se registraron varios desplazamientos colectivos y se elaboraron al menos 8 informes, algunos de los cuales se refieren al desplazamiento de 50 familias del municipio de Caluco; (iv) las víctimas del desplazamiento son invisibilizadas, pues optan por el anonimato frente al riesgo de represalias de los grupos delincuenciales; (v) algunos colectivos, como los niños y niñas de 0 a 11 años, los hombres de 18 a 25 años y las mujeres de 18 a 55 años son los más afectados; (vi) la falta de reconocimiento de la dimensión del fenómeno por el Estado es correlativa a su omisión de desarrollar políticas públicas para abordar el fenómeno de la violencia y el desplazamiento forzado como su consecuencia inmediata; (vii) la magnitud de los efectos de la violencia generalizada y del desplazamiento interno evidencian una crisis humanitaria y de protección de gran alcance; (viii) los miembros de pandillas superan en número a los efectivos de la PNC y de la Fuerza Armada; y (ix) la sensación de amenaza y de falta de investigación y castigo de los crimenes ejecutados por miembros de pandillas genera en las víctimas una falta de confianza en las instituciones públicas.

La Relatora Especial también destacó que "[e]l fenómeno del desplazamiento interno que se observa en el país se caracteriza por el desplazamiento numeroso y disperso de personas y familias de distintas localidades debido a actos de violencia, amenazas o intimidación localizados, lo que lo distingue del desplazamiento en masa que se observa durante los conflictos internos, por ejemplo. Por consiguiente, se desconoce la cifra exacta de los afectados por el desplazamiento interno dado que las víctimas buscan el anonimato y, en algunos casos, una vía de salida del país para hallar seguridad en otra parte" —párr. 11, itálicas suplidas-.

d. La Comisión Interamericana de Derechos Humanos (CIDH), en su informe temático "Movilidad humana. Estándares interamericanos", señaló que "[l]a violencia del crimen organizado es una de las principales causas de migración forzada, tanto a nivel interno como internacional, generando graves violaciones a los derechos humanos en países como Colombia, México y países de Centroamérica, en particular los países del llamado Triángulo del Norte: El Salvador, Guatemala y Honduras" _párr. 45-. Sobre la vulnerabilidad de los desplazados sostuvo que "a diferencia de los refugiados, que cruzan fronteras y pueden acceder a protección internacional, las personas desplazadas internamente se encuentran bajo la jurisdicción del Estado del que son nacionales o residentes habituales. Los refugiados, al ser sujetos de protección internacional cuentan con un estatuto especial, el cual les brinda mayor protección y visibilidad. Por el contrario, en el caso los desplazados internos, la obligación de darles protección corresponde a su propio Estado, el cual en muchas ocasiones ha sido el responsable del desplazamiento forzado de estas personas, lo cual favorece la vulnerabilidad e invisibilidad de dichas personas" — párr. 59 y 60 —.

e. Por su parte, el MJSP divulgó en marzo de 2018 los resultados de su estudio "Caracterización de la Movilidad Interna a causa de la Violencia en El Salvador", el cual aportó como prueba en este proceso. Su objeto de investigación tomó una muestra 
de 41.000 familias de distintos municipios del país, que en total suman poco más de 157.000 personas, a las cuales se practicó una encuesta. Sus conclusiones establecen que en el 22\% de esas familias al menos un familiar se había desplazado entre 2006 y 2016; sin embargo, sostienen que la violencia es la tercera causa de "movilidad humana". Contrario a las cifras que reflejan otras instituciones como la PDDH, que indica que entre 2014 y 2015 un 86\% de los casos de desplazamiento atendidos fueron directamente ocasionados por las pandillas y el porcentaje restante por otros grupos de crimen organizado, incluso efectivos de la PNC, el MJSP señaló que, "[s]egún la información recopilada, en el 1.1\% de las familias residentes a finales de 2016 al menos uno de sus integrantes se vio obligado a cambiar su lugar de residencia habitual dentro del El Salvador entre 2006 y 2016 como resultado o para evitar los efectos de hechos de violencia".

Con relación al perfil demográfico de la población desplazada por violencia, señaló que "se trata de grupos familiares jóvenes con una relativa condición de vulnerabilidad socioeconómica. El fenómeno afecta en mayor proporción a familias con miembros en edad adolescente (12-17 años) y/o joven (18-29 años), indicando un mayor riesgo de esta población al accionar de los grupos criminales $y$, por ende, una mayor probabilidad de verse obligados a movilizarse internamente. Las mujeres, como en el total de la población del país, son también mayoría en la población movilizada por violencia (54\%). La gran mayoría de la población (87\%) tuvo que movilizarse debido a la victimización directa de uno o más de los integrantes de las familias. Un alto porcentaje (40\%) reportó dos o hasta tres causas distintas que obligaron a la movilización. Las amenazas, intimidaciones o coacción constituyen la principal causa de movilización (69\% de los casos). La extorsión aparece como la segunda causa (24\%), y la situación de violencia o inseguridad en las comunidades de origen como tercera (20\%)".

Ese mismo informe indicó que la "movilidad interna" ha mostrado un crecimiento anual ascendente — salvo durante los años 2012 y 2013 - "en paralelo al nivel de incidencia de los hechos de violencia causados por los grupos criminales en el país". Asimismo, reveló que los municipios en los que se origina la migración, en la mayoría de los casos, coinciden con los principales centros poblados del país - cabeceras departamentales, a excepción de Chalatenango y San Francisco Gotera-y donde se registran altos niveles de violencia criminal. Particularmente, identificó un grupo de 6 municipios, que forman parte del área metropolitana de San Salvador-Soyapango, Tonacatepeque, Ilopango, Apopa, Mejicanos y Cuscatancingo-, con alta concentración de familias movilizadas.

Los principales hechos delictivos que, según el citado informe, dan lugar al desplazamiento por violencia son amenazas o coacción —el mayor porcentaje-, extorsión, violencia en la comunidad, homicidio, lesiones, robos, secuestros, violencia sexual y reclutamiento por agrupaciones ilícitas. Asimismo, indicó que la cifra de desplazados se ha incrementado de manera correlativa a los homicidios registrados en el país desde el año 2006. Resulta igualmente alarmante que el propio MJSP señaló en su informe que no fue posible acceder a algunos segmentos debido a 
que "las condiciones de seguridad no permitieron el ingreso de los equipos" -itálicas suplidas-.

Finalmente, con relación a los impactos para los desplazados a causa de la violencia, el MJSP destacó que estos "se ven reflejados en trastornos emocionales o psicológicos, que afectan a una alta proporción de la población (70\%). Les siguen los impactos económicos generados por el abandono de propiedades en los lugares de origen (42\%), la separación familiar temporal o definitiva en un número significativo de casos (29\%), la pérdida de fuentes de ingreso (28\%), y la interrupción de educación de los menores de edad (22\%)".

C. a. El Estado, como respuesta al fenómeno de la violencia, ha emitido legislación para prohibir las pandillas y otras organizaciones del crimen organizado. Este proceso inició con la adopción de políticas de "mano dura" y la Ley Antimaras —sobre la cual se pronunció este Tribunal en la Sentencia de fecha 1-IV-2004, Inc. 52-2003- y continuó con la emisión de otros instrumentos jurídicos como la Ley Especial contra Actos de Terrorismo - este Tribunal también se pronunció sobre ella en la citada Sentencia de fecha 24-VIII-2015, Inc. 22-2007-, la Ley contra el Crimen Organizado y Delitos de Realización Compleja y, finalmente, la Ley de Proscripción de Maras, Pandillas, Agrupaciones, Asociaciones y Organizaciones de Naturaleza Criminal, la cual establece en su art. 1 que "[s]on ilegales y quedan proscritas las llamadas pandillas o maras, tales como las autodenominadas Mara Salvatrucha, MS-trece, Pandilla 18, Mara Máquina, Mara Mao Mao, y las agrupaciones, asociaciones u organizaciones criminales tales como la autodenominada Sombra Negra; por lo que se prohibe la existencia, legalización, financiamiento y apoyo de las mismas".

El Estado ha enfocado su actuación en la represión del delito y de las organizaciones criminales, no en la prevención y el control del fenómeno ni en los derechos de las víctimas de las pandillas, particularmente de los desplazados internos.

b. La PDDH, en su publicación titulada "Informe de Registro de la Procuraduría para la Defensa de los Derechos Humanos sobre Desplazamiento Forzado", señaló que "sí existe el fenómeno de desplazamiento forzado interno a causa de la violencia delictiva en El Salvador". Esta conclusión fue respaldada con datos concretos que indican que el 86\% de víctimas de desplazamiento en los años 2014 y 2015 denunció que las pandillas las habian obligado a huir de sus residencias. Agregó que "se carece de politicas públicas que desarrollen planes, estrategias o líneas de acción para la atención y protección de las víctimas del desplazamiento, lo que puede generar indefensión de las mismas e incidir negativamente en las oportunidades de protección internacional a las que acuden cuando migran forzosamente de forma irregular y solicitan refugio" y que, si bien "la proyección del Plan El Salvador Seguro, en su Eje 4, referido a la atención de las victimas, es altamente positiva [...] las actividades contempladas aún carecen de financiamiento".

c. La Constitución separa las funciones de seguridad pública y de defensa nacional y las atribuye a distintos órganos, la PNC y la Fuerza Armada, respectivamente — sobre lo cual se pronunció esta Sala en la Sentencia de fecha 17-V-2013, Inc. 4-2012—, pero los altos indices de violencia han dado lugar desde hace algunos años a que la Fuerza 
Armada colabore con la PNC en tareas de seguridad, con base en el art. 212 de la Cn., "para el mantenimiento de la paz interna", lo cual se ha justificado, además, en la calificación de dichas organizaciones criminales como "terroristas". Esta medida fue aprobada por el Decreto Ejecutivo $n^{\circ}$ 60, del 28-IX-2009, publicado en el Diario Oficial $n^{\circ}$ 188, Tomo 385, del 9-X-2009, pero, si bien se trataría en principio de una cuestión temporal, ha sido prorrogada en distintas ocasiones (la última se extiende hasta el 31-XII-2018).

Este Tribunal se ha pronunciado sobre algunos graves señalamientos a miembros de esas corporaciones en las Sentencias de fechas 13-I-2017 y 7-III-2018, HC 40-2015 y HC 406-2015, concretamente sobre la desaparición forzada de jóvenes en el contexto de operativos de "combate" a las pandillas, por lo que existen indicios fundados de que los cuerpos de seguridad y de defensa nacional, en ocasiones, también actúan fuera de la ley.

Asimismo, se aprobaron medidas extraordinarias para los centros penitenciarios mediante el Decreto Legislativo $n^{\circ} 321$, del 1-XI-2016, pues _como se indicó en los Considerandos de ese decreto-dichos centros funcionan como sitios para planificar y dirigir delitos; sin embargo, a pesar de calificarse como "extraordinarias", dichas medidas han sido prorrogadas hasta la actualidad.

D. a. Con base en la información antes relacionada, se concluye que: (i) El Salvador sufre una grave crisis de violencia e inseguridad generada principalmente por grupos de crimen organizado, concretamente las pandillas o maras, que ejercen control territorial sobre distintas zonas geográficas del país y sus habitantes; (ii) la no intervención oportuna del Estado, por un lado, facilitó la expansión de dichas organizaciones delictivas en el territorio y el crecimiento del número de sus miembros y, por otro, permitió que fortalecieran su capacidad para delinquir y ocasionar un alto porcentaje de los crimenes que ocurren en el país, entre ellos homicidios, extorsiones, amenazas, violaciones y otros graves atentados a bienes jurídicos relevantes como la vida, la integridad física, la libertad sexual y la propiedad; (iii) sus ataques son sistemáticos $y$ con tendencia a incrementar progresivamente su intensidad, que se presentan de manera recurrente en ciertas zonas vulnerables del pais, causan terror a la población que, ante la amenaza de sufrir daños irreparables, abandonan sus hogares en búsqueda de seguridad y protección; (iv) existe un fenómeno de migración forzada de personas, tanto en el ámbito interno del territorio del Estado — desplazamiento forzado-como en el internacional —utilizando el asilo, el refugio y la migración irregular-, que tiene origen en el contexto de violencia e inseguridad que afecta gravemente a distintas zonas geográficas del país; y (v) a diferencia de los refugiados que han sido acogidos en otros países por escapar del fenómeno de la violencia y han accedido a la protección internacional que les permite iniciar planes de crecimiento y de desarrollo en sus lugares de destino, los desplazados internos se encuentran en una situación de vulnerabilidad más intensa, pues la obligación de darles protección corresponde al Estado, el cual en muchas ocasiones ha sido responsable, directa o indirectamente, del desplazamiento forzado de estas personas. 
b. También se concluye que las instituciones del Estado encargadas de la politica de seguridad tienen conocimiento del fenómeno de migración forzada de personas por la violencia de las pandillas, pero omiten categorizarlo y reconocer sus dimensiones.

i. El conocimiento de dicho fenómeno se deduce, por una parte, de la investigación realizada por el MJSP y del informe publicado por la PDDH y, por otra, del hecho que organismos como la Secretaría General del Sistema de Integración Centroamericana (SICA) hayan suscrito convenios con organismos internacionales, como el ACNUR, para abordar el fenómeno y brindar protección a la población desplazada —el informe "Atención y protección a personas desplazadas por la violencia causada por la criminalidad organizada transnacional-COT" constituye prueba de ello-.

ii. La falta de reconocimiento de sus dimensiones se colige, por un lado, del hecho que las estadísticas oficiales de "movilidad humana a causa de la violencia" —eufemismo con el que el MJSP se refiere al fenómeno-difieren de las que se reflejan en estudios publicados por otras organizaciones y, por otro, de la falta de politicas públicas de atención a las víctimas de ese fenómeno, tal como lo hizo ver la Relatora Especial sobre los derechos humanos de los desplazados internos de Naciones Unidas, en el mencionado informe sobre su visita a El Salvador en 2017 presentado ante el Consejo de Derechos Humanos de ese organismo.

c. A pesar de la minimización del problema del desplazamiento forzado por parte de la mayoría de instituciones estatales, el contexto de violencia e inseguridad que afecta al país ha sido reconocido por el Consejo Nacional de Seguridad Ciudadana y de Convivencia en el Plan El Salvador Seguro —cuya ejecución compete primordialmente al MJSP_, el cual ha concluido que "[l] a sociedad salvadoreña se encuentra afectada por elevados niveles de violencia, criminalidad y miedo que restringen la libertad de las personas, afectando su calidad de vida y la convivencia armónica, limitando sus opciones de desarrollo humano y erosionando el Estado de Derecho y la democracia. Los históricos niveles de exclusión y vulnerabilidad social, los patrones culturales que toleran, normalizan y reproducen la violencia, la debilidad institucional que provoca impunidad, la ausencia de una visión compartida sobre cómo enfrentar esta problemática junto con la dispersión de iniciativas han estimulado el establecimiento, la complejidad y la reproducción de las expresiones criminales y violentas en nuestra sociedad" —itálicas suplidas—.

3. A. En la Sentencia de fecha 1-IV-2004, Inc. 52-2003, se sostuvo que, si bien los tratados internacionales no tienen el mismo rango de la Constitución en el sistema de fuentes, la disposición constitucional que consagra su valor jurídico y posición en ese sistema —art. 144 inc. $2^{\circ}$ de la Cn.- no puede ser desatendida por el tribunal encargado de la defensa de la Constitución. De ahí que esa disposición, conectada con la concepción personalista del Estado —art. 1 y Preámbulo de la Cn.—, de la cual se deriva la regla hermenéutica en favor de la dignidad: restringir lo limitativo y expandir lo favorable a ella, no solo determina la fuerza vinculante y jerarquía normativa de los tratados internacionales de derechos humanos, sino que permite proponer una apertura normativa hacia ellos. 
B. a. En el ámbito del Derecho Internacional de los Derechos Humanos (DIDH), la Corte IDH se ha pronunciado en reiterada jurisprudencia - a partir de la interpretación de disposiciones de la CADH - sobre el fenómeno del desplazamiento forzado ocurrido en otros Estados del área - Colombia, Surinam y Guatemala- y en El Salvador durante el conflicto armado de la década de los ochentas - Caso Masacres de El Mozote y lugares aledaños vs. El Salvador, Sentencia de fecha 25-X-2012, párrs. 122 a 127-y sobre las afectaciones a derechos humanos que tienen lugar en el contexto de la migración -Opinión Consultiva OC-18/03: Condición jurídica y derechos de los migrantes indocumentados, de 17-IX-2003 y Opinión Consultiva OC-21/14: Derechos y garantías de niñas y niños en el contexto de la migración y/o en necesidad de protección internacional, de fecha 19-VIII-2014-.

Por ejemplo, en el Caso Masacres de Ituango vs. Colombia, Sentencia de fecha 1VII-2006, el tribunal se pronunció sobre el desplazamiento colectivo de civiles en el municipio de Ituango, Colombia, motivada por graves hechos —entre ellos una masacre - perpetrados por grupos paramilitares o de "autodefensa". Asimismo, en el Caso Chitay Nech y otros vs. Guatemala, Sentencia de fecha 25-V-2010, también abordó el desplazamiento de la población indigena maya durante el conflicto interno guatemalteco, en el que no solo participaron autoridades estatales sino también grupos paramilitares y las "Patrullas de Autodefensa Civil".

En este último caso, la Corte IDH señaló que "[e]l artículo 22.1 de la Convención reconoce el derecho de circulación y de residencia. En este sentido, la Corte ha establecido en otros casos que este artículo también protege el derecho a no ser desplazado forzadamente dentro de un Estado Parte" —párr. 139, itálicas suplidas—. Además, sostuvo que "en razón de la complejidad del fenómeno del desplazamiento interno y de la amplia gama de derechos humanos que afecta o se ponen en riesgo, y en atención a las circunstancias de especial vulnerabilidad e indefensión en que generalmente se encuentran los desplazados, su situación puede ser entendida como una condición de facto de desprotección. Esta situación, conforme a la Convención Americana, obliga a los Estados a adoptar medidas de carácter positivo para revertir los efectos de su condición de debilidad, vulnerabilidad e indefensión, incluso vis-à-vis las actuaciones y prácticas de terceros particulares" —párr. 141-.

Agregó que "el derecho de circulación y de residencia puede ser vulnerado por restricciones de facto si el Estado no ha establecido las condiciones ni provisto los medios que permiten ejercerlo, por ejemplo cuando una persona es víctima de amenazas u hostigamientos y el Estado no provee las garantías necesarias, para que pueda transitar y residir libremente en el territorio de que se trate, incluso cuando las amenazas y hostigamientos provienen de actores no estatales" —párr. 142, itálicas suplidas-.

Finalmente, se pronunció sobre las obligaciones a cargo de los Estados respecto de la investigación y sanción de los responsables y de proveer las condiciones necesarias para un retorno digno y seguro a su lugar de residencia habitual o su reasentamiento voluntario en otra parte del país. Para ello, se debe garantizar su participación plena en la planificación y gestión de su regreso o reintegración" —párr. 149, itálicas suplidas-. 
b. Esos criterios han sido retomados por la Corte IDH en otros pronunciamientos sobre la misma temática: Caso de la Comunidad Moiwana vs. Surinam, Caso de las Masacres de Río Negro vs. Guatemala, Caso de la Masacre de Mapiripán vs. Colombia, Caso de las Comunidades Afrodescendientes Desplazadas de la Cuenca del Río Cacarica (Operación Génesis) vs. Colombia, Caso Defensor de Derechos Humanos y otros vs. Guatemala y Caso de la Masacre de Pueblo Bello vs. Colombia; sentencias de fechas 15-VI-2005, 4-IX-2012, 15-IX-2005, 20-XI2013, 28-VIII-2014 y 31-I-2006, respectivamente.

Además, están en consonancia con los estándares de protección que algunas áreas especializadas del Derecho Internacional — como el DIDH, el Derecho Internacional Humanitario (DIH) y el Derecho Internacional de los Refugiados (DIR)_confieren a los migrantes que han huido de sus residencias en virtud de situaciones que trascienden su capacidad de decisión.

C. En relación con los desplazados internos no existe un tratado especializado que se centre exclusivamente en su protección - lo cual no excluye la aplicación, incluso de forma analógica, de tratados del DIDH y del DIH-. No obstante, si existen normas declarativas que son plenamente aplicables, por ejemplo las declaraciones de principios y compromisos adoptados en conferencias internacionales que son útiles para interpretar y para complementar los tratados. Por ejemplo, los Principios Rectores de los Desplazamientos Internos, citados anteriormente, definen dos ámbitos principales en los que deben intervenir los Estados en beneficio de la población desplazada: (i) el reconocimiento de ciertos derechos; y (ii) la asistencia humanitaria y su protección.

a. En el primer ámbito los referidos principios enfatizan en el deber de garantizar a los desplazados internos, en igualdad de condiciones, los mismos derechos que el Derecho interno y el internacional reconocen a su favor, sin distinción de raza, color, sexo, idioma, religión o convicciones, opinión politica o de cualquier otra indole, origen nacional, étnico o social, condición jurídica o social, edad, discapacidad, posición económica, descendencia o cualquier otro criterio similar.

b. Las obligaciones de asistencia humanitaria y de protección están consignadas en los principios 2, 6 y siguientes. El principio 2 establece: “1. Las autoridades nacionales tienen la obligación y la responsabilidad primarias de proporcionar protección y asistencia humanitaria a los desplazados internos que se encuentren en el ámbito de su jurisdicción. 2. Los desplazados internos tienen derecho a solicitar y recibir protección y asistencia humanitaria de esas autoridades. No serán perseguidos ni castigados por formular esa solicitud". El principio 6 reconoce expresamente a toda persona el "derecho a la protección contra desplazamientos arbitrarios que le alejen de su hogar o de su lugar de residencia habitual". Con relación a la asistencia humanitaria, el principio 7 señala el deber de asegurar a los desplazados condiciones de seguridad, alimentación, salud e higiene.

Asimismo, conceden una especial protección a ciertos grupos que podrían encontrarse en una situación de vulnerabilidad acentuada, por ejemplo los niños y las mujeres, pero también establecen la obligación de los Estados de "tomar medidas de protección contra los desplazamientos de pueblos indígenas, minorías, campesinos, pastores y otros 
grupos que experimentan una dependencia especial de su tierra o un apego particular a ella — principio 9-. Finalmente, con relación a la asistencia humanitaria para garantizar a los desplazados una vida digna, el principio 18.2 refiere la necesidad de que se les proporcionen alimentos indispensables y agua potable, cobijo y alojamiento básicos, vestido adecuado y servicios médicos y de saneamiento indispensables.

D. Cabe señalar también, de manera ilustrativa, que en el ámbito del Derecho comparado un pronunciamiento paradigmático sobre la protección de los desplazados internos es la Sentencia de fecha 22-I-2004, T-025, pronunciada por la Corte Constitucional de Colombia, en la cual el citado tribunal señaló que "[e]xisten ciertos derechos mínimos de la población desplazada que deben ser satisfechos en cualquier circunstancia por las autoridades [...], puesto que en ello se juega la subsistencia digna de las personas en esta situación". Asimismo, indicó que en razón de "la multiplicidad de derechos constitucionales afectados por el desplazamiento, y atendiendo a las aludidas circunstancias de especial debilidad, vulnerabilidad e indefensión en la que se encuentran los desplazados", estos tienen un "derecho a recibir en forma urgente un trato preferente por parte del Estado", que "debe caracterizarse, ante todo, por la prontitud en la atención a las necesidades" —itálicas suplidas-.

Tanto el aludido tribunal constitucional como la Corte IDH coinciden en que la condición de desplazado viene dada por el "mero hecho de haberse visto compelido a abandonar el lugar de residencia habitual" —Caso de las Masacres de Ituango, párr. 214_.

VI. 1. A. a. Las partes aportaron como prueba, entre otros, los siguientes documentos: (i) copias de los resúmenes iniciales de las denuncias efectuadas por el Demandante 2 y una persona ajena a este proceso ante la PDDH, en las cuales reclamaban por los hechos ocurridos en el municipio de Berlin; (ii) copia del acta de fecha 18-XII2016, en la cual consta que un agente de la PNC denunció ante el Departamento de Investigaciones de la Delegación de Usulután su versión de los hechos ocurridos en el municipio de Berlin; (iii) informe "marco referencial", en el que se consigna la ubicación geográfica del cantón del municipio de Berlín al que los pretensores se mudaron desde Delgado, que en él no hay presencia de pandilleros y que, si bien el municipio tiene la presencia de dos pandilleros, estos no tienen más antecedentes penales que un hecho ocurrido en 2014; (iv) copia del acta de inspección realizada en la calle principal del referido cantón a las 2.10 horas del 18-XII-2016, con la participación de la Policía Técnica y Científica de la PNC, en la cual consta que se encontraron casquillos de bala en el lugar; (v) copia de acta de inspección de cadáver realizada en el Hospital Nacional de Jiquilisco a las 5:20 horas del 18-XII-2017 —se consigna el año 2017, aunque los hechos aparentemente ocurrieron en 2016 - en la cual se hizo constar que la víctima - una señora- recibió un impacto de bala en la parte baja del abdomen, la cual causó su muerte; (vi) certificación del expediente SS-0236-2017 y acumulado, expedida por la secretaria general de la PDDH, en la cual consta el trámite de las denuncias interpuestas ante dicha institución por el Demandante 2 y por otra persona, quienes acusaron de abuso de poder a miembros de la PNC destacados en Jiquilisco y El Triunfo, en el contexto de la fiesta ocurrida en el citado cantón el municipio de Berlín la noche del 17-XII-2017; 
(vii) copias de las actas policiales incorporadas al expediente del homicidio ocurrido en el mencionado cantón, en las cuales constan las versiones de los hechos ocurridos la noche del 17-XII-2016 en dicho lugar; (viii) copia del informe final "Caracterización de la movilidad interna a causa de la violencia en El Salvador"; (ix) copia del Plan El Salvador Seguro, en el que se describen los ejes centrales de la politica de seguridad que debe implementar el MJSP; y (x) copia del anteproyecto de Ley Especial para la Atención, Protección y Reparación Integral a Víctimas de Delito y Violencia.

Asimismo, se presentó como prueba una copia del expediente que lleva la Oficina Fiscal de Mejicanos con relación a los delitos de homicidio en grado de tentativa y violación de los cuales fueron víctimas los miembros del grupo familiar de los Demandantes 5 y 6, imputados a varios sujetos miembros de la Pandilla 18 Revolucionarios, quienes fueron privados de libertad el 12-X-2016. En dicho expediente constan, entre otros, los siguientes datos: (i) las entrevistas realizadas en sede policial a las víctimas y a los agentes captores, el reconocimiento médico forense de lesiones a una de las víctimas y ginecológico de la mujer y de la niña que denunciaron haber sido violadas, así como las actas de recolección de evidencias, entre otras diligencias urgentes de comprobación; (ii) la asignación del caso a la Unidad de Delitos Relativos a la Niñez, Adolescencia y Mujer en su Relación Familiar — no a la Unidad de Vida, como señalaron los demandantes-; (iii) la asignación de claves a las victimas por parte de la UTE del Sector de Justicia, sin que conste la adopción de medidas extraordinarias de protección como su resguardo en algún albergue de los que dispone esa institución, a pesar de la gravedad de los hechos denunciados; (iv) la autorización del secuestro de ciertos objetos emitida por el Juzgado Tercero de Paz de Delgado; (v) la presentación posterior del caso ante el Juzgado Segundo de Menores de San Salvador, el cual ordenó medidas cautelares, para uno de los detenidos la medida de internamiento y para el otro medidas sustitutivas, y señaló el reconocimiento en fila de los menores; (vi) que el 6-I-2017 el Departamento de Investigaciones de la PNC de Delgado informó a la Subregional de Mejicanos de la FGR que las victimas le habian comunicado por vía telefónica que no continuarian con el proceso porque se irían del país; (vii) que el 9-I-2017 el Departamento Penal Juvenil de la FGR de Mejicanos decidió no promover la acción penal, por la información proporcionada por la PNC en fecha 6-I-2017; (viii) la resolución de fecha 10-I-2017, emitida por el Juez Segundo de Menores de San Salvador, en la que sobreseyó provisionalmente el proceso en virtud de lo solicitado por la agente auxiliar del titular de la FGR; y (ix) los movimientos migratorios de las víctimas de esos delitos, en los que consta que salieron del país en el mes de julio de 2017.

b. Según lo dispuesto en el art. 331 del Código Procesal Civil y Mercantil (C.Pr.C.M.), de aplicación supletoria a los procesos de amparo, con la certificación antes relacionada, la cual fue expedida por una funcionaria de la PDDH en ejercicio de sus competencias, se han comprobado los hechos que en esa certificación se consignan, esto es, que uno de los demandantes y otra persona denunciaron ante dicha institución el supuesto acoso policial a raiz de los hechos ocurridos en el municipio de Berlín en diciembre de 2016. De igual manera, en razón de lo dispuesto en los arts. 330 inc. $2^{\circ}$ y 343 del C.Pr.C.M., con las copias simples antes mencionadas, dado que no se acreditó su falsedad ni la de 
los documentos originales que reproducen, se han comprobado de manera fehaciente los datos contenidos en ellas.

B. a. Asimismo, en la audiencia probatoria se produjo la declaración de propia parte del Demandante 2, quien sostuvo que es miembro y lider de una familia de 33 personas, las cuales han sido víctimas de desplazamiento forzado en dos ocasiones.

Declaró que en el año 2016 residía en un cantón del municipio de Berlín, pero algunos miembros de su familia residian en Delgado. Sus familiares de Delgado eran amenazados por miembros de la Pandilla 18 y también por la pandilla contraria debido a que dos de sus hermanos eran efectivos militares. Por ello solicitaron auxilio a la PNC y a la FGR, ante quienes interpusieron denuncia por los delitos de extorsión y amenazas. Las autoridades públicas les manifestaron que iniciarían las diligencias; sin embargo, nunca les informaron sobre el programa de protección de víctimas y testigos ni que podrian tener la calidad de sujetos de protección. Finalmente, sus hermanos y sobrinos se trasladaron, por sus propios medios, al cantón en el que él residía en el municipio de Berlin, abandonando su trabajo y estudios.

El declarante aseveró que era líder de una ADESCO y ello le permitió coordinar el traslado de su familia a la comunidad en que residia, "con la certeza de que ahi no correrían peligro, porque en ese lugar no habia pandilleros". Sin embargo, un mes y medio después, en el contexto de una fiesta navideña celebrada en diciembre de 2016, las autoridades antipandillas intervinieron el lugar en búsqueda de pandilleros y en ese operativo hubo disparos. Uno de ellos hirió a su madre, quien falleció en el hospital de Jiquilisco.

Cuando esto ocurrió estaba oscuro y había "caos". Vio patrullas frente su casa y fue apuntado con un arma y amenazado por un policía, aun cuando le explicó que él no era pandillero. Posteriormente escuchó los gritos de su madre y preguntó a las personas que se encontraban cerca del lugar quién habia disparado, contestándole estas que los policías y que su madre estaba herida. Esa noche denunció los hechos ante el jefe de la PNC de Berlín, quien le manifestó que esperara las investigaciones y no opinara anticipadamente.

Dicha autoridad no tomó nota de los hechos y "todo quedó en el ámbito de lo verbal, de palabra", pese a que "fue al lugar y verificó todas la vainillas que habian quedado". Luego hubo dos detonaciones de arma cerca de su casa, pero le aseguraron que realizarian las diligencias de investigación y le instaron a que se encerrara en su casa y no contaminaran la escena. Después se dio cuenta de que la policía manejaba una versión distinta de los hechos, en la cual se afirmaba que se había encontrado un arma frente a la casa del declarante "para establecer que ellos habian disparado primero y justificar el ataque de la policía". El demandante 4, que era militar, aparentemente le dijo a los policías que "pagarían con justicia", pero estos le contestaron que correría la misma suerte.

Esta advertencia fue tomada como una amenaza por su familia, de modo que, finalmente, después de enterrar a su madre, huyeron a San Salvador, porque consideraron que no podian denunciar en Berlín. Buscó ayuda en la sede de la FGR ubicada en Santa Elena, pero la recepcionista de dicha entidad, al ver su DUI, le dijo que no podía 
ayudarle porque "no era del lugar". Entonces acudió a la sede ubicada en La Sultana, pero el fiscal que lo atendió le dijo también que no podía ayudarle. Después fue a la Inspectoría General de la PNC, donde sí le tomaron su testimonio, lo ingresaron al sistema y le manifestaron que con los datos aportados se iniciaría una investigación. Expresó que un investigador de Asuntos Internos de San Miguel lo llamó hasta enero, se reunió con él, le recibió su testimonio y tomó nota de lo declarado, pero se limitó a pedirle que esperara. En el mes de marzo le informó que la investigación estaba terminada y que el caso pasaría a la sede de la FGR en Usulután, pero le dijo que no opinara sobre los hechos porque no era abogado. Meses después se le pidió que se personara a la FGR, pero la recepcionista le afirmó que los hechos que constaban en su expediente no eran sobre la muerte de su madre, sino sobre un feminicidio que debía tramitarse en San Miguel. Posteriormente contactó por teléfono a un fiscal de San Miguel, pero tampoco se le brindó información. Le dijeron que debía comparecer con la documentación correspondiente para recabar información del supuesto feminicidio. Finalmente, lo remitieron nuevamente a Usulután y le dijeron que se dirigiera a la PNC del lugar de los hechos, es decir, donde laboraban los sujetos que, a su juicio, habian manipulado los hechos relativos a la muerte de su madre y que estaban involucrados.

En definitiva, asistió a diferentes oficinas fiscales — Santa Elena, La Sultana, Usulután y San Miguel_, pero en ninguna de las gestiones que realizó en esas oficinas se le recibió por escrito su declaración, salvo en la PDDH y en la Inspectoría de la PNC en San Miguel, donde sí se tomó nota de su denuncia y se remitió a la sede la FGR en Usulután; de esa forma ingresó su caso. Hasta el momento no se le ha brindado respuesta a sus denuncias y ninguna de las autoridades policiales y fiscales que lo atendieron le informó las medidas ordinarias y extraordinarias que podian activarse a su favor en virtud de lo previsto en la LEPVT.

b. La declaración de parte debe ser valorada conforme a la sana crítica -arts. 216 y 417 del C.Pr.C.M-. Con relación a ella, se considera que los hechos narrados por el declarante son coincidentes entre sí y que este se mostró espontáneo al hablar. Además, no se encuentra razón para dudar del declarante, pues no se ha aportado al proceso prueba que ponga en duda su credibilidad o la confiabilidad de la información que proporcionó. c. En relación con la aludida declaración, el apoderado de la Comisión Coordinadora y de la titular de la UTE del Sector de Justicia solicitó en audiencia que se procesara al declarante por el delito de falso testimonio, específicamente porque manifestó un motivo para abandonar el albergue que le fue proporcionado distinto al que consta en la hoja de abandono de ese lugar, referido a un hecho de violencia intrafamiliar.

Respecto a dicha petición, se advierte que la razón por la cual el Demandante 2 abandonó el albergue que le fue facilitado es una cuestión que no guarda relación con el objeto de este proceso; sin embargo, aquel manifestó que su familia abandonó el país y él fue acogido por una organización que le prestó auxilio por su condición de desplazado. Precisamente, uno de los derechos de los desplazados internos es el de decidir si se reasientan en otro lugar del territorio nacional o solicitan asilo o refugio a otro Estado. De ahi que, independientemente de que el Demandante 2 haya abandonado o no el 
albergue que le fue proporcionado, ese hecho no modifica su calidad de desplazado, lo que, en esencia, pretendía acreditar con su declaración.

C. a. La Comisión Coordinadora y la titular de la UTE del Sector de Justicia aportaron medios de almacenamiento de información (CD) que contienen documentos en formato electrónico sobre las labores institucionales que han realizado en los últimos años, el marco institucional de sus funciones y las diligencias que realizaron para proporcionar albergue a los peticionarios en el marco del trámite del presente amparo.

Entre los documentos presentados conjuntamente por dichas instituciones constan los siguientes: (i) acta de fecha 9-III-2018, en la cual consta que la UTE del Sector de Justicia autorizó continuar "fortaleciendo los ejercicios sectoriales encaminados al fortalecimiento del Área de Protección a Víctimas y Testigos, con la finalidad de mejorar los niveles de respuesta a la demanda, considerándose las limitadas capacidades financieras"; (ii) memoria de labores del año 2017, en la que se reflejan algunas propuestas de innovación en materia penal y procesal penal como la vigilancia electrónica, sus aportes a la justicia penal juvenil, capacitaciones e investigación jurídica, entre otros rubros; (iii) presupuesto institucional de la UTE, que refleja una asignación total de $\$ 4.962 .782$, de los cuales $\$ 3.770 .582$-que comprende el pago de remuneraciones, adquisiciones de bienes o servicios y gastos financieros - se destinan al programa de protección de víctimas, testigos y cualquier otra persona que se encuentra en riesgo o peligro debido a su intervención en la investigación de un delito o proceso judicial; y (iv) nota de fecha 12-IX-2017, en la cual la Comisión Coordinadora solicitó al "Ministro" un incremento a su presupuesto para mejorar la atención de victimas y testigos en el contexto de ejecución del Plan El Salvador Seguro.

El informe de labores del año 2017 refleja: (i) que el número de solicitudes de atención a víctimas y testigos en ese año fue de 2.782 y que los principales delitos que motivaron dichas solicitudes fueron homicidios, extorsiones, violaciones y agresiones sexuales, robos, delitos relacionados con organizaciones terroristas y privación de libertad; (ii) que las zonas del país que reflejaron una mayor concentración de solicitudes de medidas de protección ordinarias y extraordinarias fueron la central y la oriental; (iii) que los solicitantes de medidas fueron 2.270 hombres, 1.028 mujeres y 69 personas jurídicas; y (iv) que se adoptaron más de 3.000 medidas ordinarias y extraordinarias de protección, pero todas en el contexto de investigaciones y procesos penales, de modo que no se informó concretamente sobre las víctimas de desplazamiento forzado.

b. Los medios de almacenamiento aportados hacen prueba de conformidad con los arts. 397 y 416 del C.Pr.C.M., ya que no se controvirtió la autenticidad de la información que contienen, el contenido de algunos de ellos se reproduce en impresiones que fueron incorporadas al expediente y no fueron cuestionados por el resto de partes intervinientes.

D. a. Al valorar conjuntamente los elementos probatorios aportados conforme a las reglas de la sana crítica, se tienen por establecidos los siguientes hechos: (i) los peticionarios conforman un grupo familiar de 33 personas, que en su mayoría residió hasta finales de 2016 en Delgado; (ii) dos de los miembros de la familia son militares $y$, por ello, los integrantes de dicho grupo fueron objeto de acoso de pandilleros del 
Barrio 18 que ejercen control territorial sobre la comunidad en la que habitaban; (iii) el 12-X-2016 los Demandantes 5 y 6 denunciaron los hechos ocurridos en su vivienda la noche anterior, los cuales describieron como lesiones, amenazas y violaciones; (iv) el 17-X-2016 la Demandante 1 y su esposo interpusieron una denuncia en la División Antiextorsiones de la PNC referida a la extorsión por la cantidad de $\$ 5.000$ que les exigieron pandilleros la noche del dia anterior; (v) los hechos descritos forzaron a la familia a desplazarse a un cantón del municipio de Berlin, donde residian otros miembros de esa familia, en busca de seguridad y protección, pues el Demandante 2 era líder de una ADESCO y podía colaborar con su reubicación; (vi) en ese lugar, una noche del mes de diciembre de 2016, miembros de la PNC realizaron un cateo en busca de pandilleros $y$, en un hecho confuso, se produjeron disparos de arma de fuego, uno de los cuales lesionó a la madre del Demandante 2, que falleció en el Hospital Nacional de Jiquilisco; (vii) al día siguiente el Demandante 2 denunció ante el jefe de la Subdelegación de la PNC de Berlín esos hechos y acusó a los efectivos policiales que habian realizado el cateo de ser los responsables de la muerte de su madre, pero no se dejó constancia de su denuncia; (viii) los agentes de la PNC manejan una versión de los hechos distinta a la de los demandantes, situación que provocó problemas con dichos agentes y el verse nuevamente forzados a un desplazamiento, esta vez hacia San Salvador; y (ix) con posterioridad, todos los miembros de la familia, excepto el Demandante 2, por el temor a ser victimas de otros hechos de igual gravedad, abandonaron el país.

b. Con relación a las investigaciones realizadas por las autoridades policiales y fiscales respecto de los hechos denunciados por los peticionarios, se ha establecido que: (i) el jefe de la División Antiextorsiones de la PNC recibió la denuncia presentada por el Demandante 1, a quien asignó una clave para identificarlo, pero no continuó con la investigación respectiva, lo cual justificó en que no había tenido la colaboración de la víctima; (ii) el jefe de la División Central de Investigaciones de la PNC no aportó pruebas sobre las investigaciones realizadas ni de su colaboración a la FGR respecto de los hechos que fueron denunciados ante esa dependencia de la PNC; (iii) el jefe de la Subdelegación de la PNC de Berlin sostuvo una versión de los hechos acontecidos el 17-XII-2016 distinta a la que el Demandante 2 y otra persona plantearon ante la PDDH, denunciando a agentes de la PNC por abuso; y (iv) la investigación sobre los hechos de los cuales fueron víctimas los Demandantes 5 y 6 junto a sus hijos fue asignada a la Unidad de Delitos Relativos a la Niñez, Adolescencia y Mujer en su Relación Familiar de la FGR y, posteriormente, el Departamento Penal Juvenil de la FGR decidió no continuar con la acción penal porque las víctimas abandonarían el país, lo cual provocó que en enero de 2017 el Juez Segundo de Menores de San Salvador sobreseyera provisionalmente el proceso, pese a que las víctimas abandonaron el país hasta julio de ese mismo año.

En definitiva, las autoridades policiales y fiscales demandadas no acreditaron en el proceso que hayan realizado investigaciones exhaustivas y concluyentes sobre los hechos denunciados ante ellas. Y es que, si bien la UTE del Sector de Justicia asignó claves a algunos de los demandantes en el contexto de esas investigaciones, no consta que se les hayan proporcionado medidas de protección y de asistencia adicionales, como la reclusión en alguno de los albergues para proteger sus vidas y su integridad, a pesar 
de la gravedad de los hechos denunciados y del riesgo acentuado que corría esa familia debido a que dos de sus familiares eran militares $y$, por ello, potenciales víctimas de ataques de los grupos criminales.

c. La Comisión Coordinadora y la titular de la UTE del Sector de Justicia, así como el titular del MJSP, comprobaron que han realizado distintas actividades, en el marco de sus competencias, para abordar el fenómeno de la violencia y la protección de víctimas y testigos; sin embargo, no registran atención a victimas de desplazamiento forzado, sino únicamente a víctimas en el contexto de investigaciones y procesos penales. Tampoco acreditaron que hayan participado en la elaboración de politicas y protocolos de actuación referidos específicamente a las victimas de desplazamiento forzado, a fin de trascender la naturaleza instrumental que les asigna la LEPVT. Por el contrario, se excusaron en el argumento que cuentan con pocos recursos en sus presupuestos para ampliar la cobertura de los programas de protección de víctimas y testigos, pero acudian a la cooperación de otras instituciones públicas y privadas para atender las necesidades básicas de las víctimas y trasladarlas, cuando era posible, a otros países al finalizar las investigaciones y los procesos penales.

d. La Asamblea Legislativa, por su parte, no acreditó que, en el contexto de violencia y de inseguridad que atraviesa el país, haya procedido a la revisión de la legislación especial sobre victimas y testigos para incorporar y categorizar a las victimas de desplazamiento forzado como sujetos de derechos, de protección y de asistencia humanitaria. E. En consecuencia, los hechos antes descritos y lo expuesto en el Considerando IV.2 de esta sentencia como análisis del contexto en que estos acontecieron, permiten inferir que los peticionarios y los integrantes de su grupo familiar han sido víctimas de desplazamiento forzado, en un primer momento, como consecuencia del acoso y de graves atentados que pandilleros del Barrio 18 efectuaron en su contra y, en un segundo momento, por un hecho de violencia no investigado ni esclarecido que involucró a agentes de la PNC y provocó el fallecimiento de la madre del Demandante 2.

2. Corresponde en este apartado analizar las omisiones imputadas a los jefes de la División Central de Investigaciones, de la División Antiextorsiones, de la Subdelegación de Berlín, todos de la PNC, y de la Unidad de Vida e Integridad Física de la Oficina Fiscal de Mejicanos de investigar las denuncias efectuadas por algunos de los actores en fechas 12X-2016, 17-X-2016 y 17-XII-2016, así como de ordenar las medidas de protección necesarias para que estos pudieran circular libremente hacia y en el entorno de sus viviendas.

A. a. En cuanto a la denuncia formulada por los Demandantes 5 y 6 en la Oficina Fiscal de Mejicanos en fecha 12-X-2016, en relación con los hechos acontecidos en su vivienda el 11-X-2016, se advierte que inicialmente las autoridades policiales y fiscales correspondientes actuaron de forma diligente, pues en el expediente fiscal se refiere que hubo capturas en flagrancia y que se realizaron actos urgentes de comprobación como inspección en la vivienda, recolección de evidencias, práctica de entrevistas a las víctimas y a los agentes captores, reconocimiento de sangre, genitales y sanidad en el 
Instituto de Medicina Legal de la CSJ. Asimismo, consta que se requirió oportunamente la autorización del secuestro de las evidencias recolectadas y que el juez Segundo de Menores de San Salvador ordenó medidas cautelares y el reconocimiento en fila de los menores capturados.

b. Sin embargo, luego de ser informado por un investigador de la PNC sobre la intención de las víctimas de abandonar el país, el Departamento Penal Juvenil de la Oficina Fiscal de Mejicanos decidió no continuar con el proceso penal respectivo, sin que previamente haya intentado comunicarse con las víctimas para ofrecerles medidas de protección o, al menos, para requerir como prueba anticipada su declaración ante una autoridad judicial, con base en las disposiciones de la legislación procesal aplicable al caso.

Por el contrario, se advierte que la decisión de no continuar con el proceso penal respectivo fue adoptada aun cuando en el expediente constaban: (i) las entrevistas realizadas a las tres víctimas y a los agentes captores; $y$ (ii) los resultados del reconocimiento de personas, de los reconocimientos médicos forenses de lesiones, genitales y sanidad practicados a las víctimas, del análisis serológico a una de las víctimas y del análisis quimico de evidencias recolectadas en la vivienda de aquellas. Lo anterior se constata con la resolución emitida por la agente fiscal encargada del caso, en la cual concluyó que, "no obstante se cuenta con indicios, recolectados en la investigación", no era posible "fundamentar una [...] acusación en contra de los menores, ya que no contamos con la voluntad de las víctimas para poder continuar con el presente proceso".

En ese sentido, resulta injustificado que, con la sola comunicación realizada por medio de una llamada telefónica entre un investigador de la PNC y una de las víctimas, se haya decidido no continuar con el proceso penal respectivo, sobre todo si se toma en cuenta que: (i) los delitos investigados eran de acción pública, por lo que no requerían de la autorización de las víctimas para continuar con el proceso; (ii) una de las víctimas de violación fue una niña de 12 años, por lo que la investigación del delito debía realizarse con mayor diligencia; $y$ (iii) la agente fiscal asignada al caso conocía que existían indicios suficientes —incluso prueba técnica-de que dos de las víctimas habian sido objeto de violación y otra de lesiones.

c. En relación con el hecho de que una niña haya sido víctima del delito de violación, es preciso señalar que la Corte IDH, en el Caso V.R.P. y V.P.C. vs. Nicaragua, Sentencia de fecha 8-III-2018, afirmó que "la violación es causa de severos daños físicos y psicológicos, que se intensifican cuando la víctima es una niña" —párr. 313—. De ahi que la negligencia en la investigación penal "frente a casos individuales de violencia contra la mujer propicia un ambiente de impunidad que facilita y promueve la repetición de los hechos de violencia en general y envía un mensaje según el cual la violencia contra la mujer puede ser tolerada y aceptada, lo que favorece su perpetuación y la aceptación social del fenómeno, el sentimiento y la sensación de inseguridad de las mujeres, así como una persistente desconfianza de estas en el sistema de administración de justicia. Dicha ineficacia o indiferencia constituye en sí misma una discriminación de la mujer en el acceso a la justicia" —párr. 291-. 
Aunado a ello, no se ha acreditado que se hayan adoptado medidas de protección para que las víctimas no fueran expuestas frente a sus agresores, que el reconocimiento respectivo se realizara en condiciones que resguardaran su identidad y que se haya informado a aquellas la posibilidad de solicitar resguardo en un albergue mientras se tramitara el proceso penal correspondiente, por lo que se les negó la posibilidad de recibir la protección que les confiere la LEPVT.

d. Ahora bien, en la audiencia probatoria la jefa de la Unidad de Vida de la Oficina Fiscal de Mejicanos señaló que carecía de legitimación pasiva porque la investigación fue asignada a la Unidad de Delitos Relativos a la Niñez, Adolescencia y Mujer en su Relación Familiar y, además, en el transcurso de este proceso se ha comprobado que el caso fue asignado posteriormente al Departamento Penal Juvenil de la FGR, por lo que resulta procedente sobreseer a la referida autoridad por la vulneración constitucional que los actores le atribuyeron.

No obstante, del contenido de la prueba aportada al proceso se deduce, por una parte, la gravedad de los hechos denunciados por los demandantes ante la FGR — tanto por el tipo de delitos de que se trata como por la situación de vulnerabilidad en que se encontraban las víctimas de ellos - y, por otro, que en el desarrollo de la investigación intervinieron distintas autoridades de esa institución, a pesar de lo cual no se continuó con la investigación de los referidos hechos, aun contando con elementos de convicción suficientes para ello y que los delitos en cuestión eran de acción pública, por lo que no se requería la anuencia de las víctimas para requerir su enjuiciamiento.

En virtud de ello, con el objeto de no dejar impune la transgresión constitucional antes advertida y en atención a las circunstancias particulares del caso, resulta procedente ordenar al titular de la FGR, a quien constitucionalmente le corresponde la conducción de esa institución y la investigación y el ejercicio de la acción penal, que deduzca las responsabilidades administrativas derivadas de la falta de diligencia y, en caso de ser posible, promover la vía de reparación de los derechos fundamentales de las víctimas.

B. Con relación a la denuncia efectuada por el Demandante 1 el 17-X-2016 en la División Antiextorsiones de la PNC por los hechos acontecidos el 16-X-2016 que denotaban la probable existencia del delito de extorsión, se advierte que en el transcurso de este proceso de amparo no se acreditó que las autoridades policiales respectivas hayan realizado las investigaciones para determinar la responsabilidad penal de los delincuentes, pues el jefe de la referida División se limitó a afirmar que no había contado con la colaboración de la víctima.

Por su parte, el jefe de la División Central de Investigaciones de la PNC se limitó a señalar que aún no había asumido ese cargo en la fecha en que presentó la denuncia y que en las "consignas" que habia recibido no estaba registrado el caso. Dicha autoridad no investigó posteriormente si, al interior de la unidad que dirige, se había recibido la denuncia en cuestión.

C. Finalmente, respecto del hecho denunciado por el Demandante 2, ocurrido en el municipio de Berlín, no se tiene certeza de si este fue responsabilidad de policías o de pandilleros. Únicamente se tiene por establecido que ocurrió en el contexto de 
un operativo de búsqueda de pandilleros y que, producto de un disparo, la madre del denunciante falleció, lo cual motivó un segundo desplazamiento de los peticionarios y sus núcleos familiares.

Para que el derecho a la protección en la defensa jurisdiccional y no jurisdiccional del peticionario sea efectivamente tutelado, es necesario que ese hecho sea objeto de una investigación exhaustiva, seria, diligente y concluyente, en la que se pueda determinar la responsabilidad penal respecto del citado homicidio, situación que no se comprobó en el presente amparo que haya sido realizada por las autoridades policiales competentes.

D. En consecuencia, se concluye que las omisiones en que incurrieron las referidas autoridades policiales de realizar investigaciones exhaustivas, diligentes y concluyentes sobre los hechos denunciados por los peticionarios, así como de brindarles las medidas de protección necesarias para resguardar su integridad física y evitar que tuviesen que abandonar sus hogares, vulneraron los derechos a la protección en la defensa jurisdiccional y no jurisdiccional de los derechos, a la seguridad material — por el riesgo inminente de sufrir ataques de pandilleros o de policías-, a la protección de la familia, a las libertades de circulación y de residencia, y a la propiedad de los actores, ya que producto de la falta de diligencia de las autoridades mencionadas fueron víctimas de desplazamiento interno en dos ocasiones. Por consiguiente, resulta procedente declarar que ha lugar el amparo requerido con relación a este punto de la pretensión planteada.

3. Corresponde en este apartado examinar la omisión atribuida al titular del MJSP, a la Asamblea Legislativa, a la Comisión Coordinadora y a la titular de la UTE del Sector de Justicia de emitir, elaborar y promover leyes secundarias, normativa reglamentaria, politicas, programas y protocolos de actuación para garantizar la protección de las victimas de desplazamiento forzado interno.

A. a. El art. 131 ord. $5^{\circ}$ de la Cn. atribuye a la Asamblea Legislativa la competencia de legislar y de actualizar el ordenamiento mediante la interpretación auténtica, la reforma y la derogación de las leyes.

En la Sentencia de fecha 13-X-2010, Inc. 17-2006, se dijo que una característica de los derechos fundamentales es que, tratándose de barreras frente al legislador, su plena eficacia está también necesitada de colaboración legislativa. Los derechos fundamentales son, a la vez, limite frente a la ley y objeto de su regulación. Existe una vinculación positiva que impone al legislador una tarea de promoción de los derechos fundamentales. Ello se justifica en la relativa indeterminación de los enunciados constitucionales que proclaman los derechos fundamentales. En lugar de dejar enteramente la determinación de su alcance en manos de la casuística jurisdiccional, es necesario que estas cuestiones sean abordadas de manera general por el legislador.

En la Sentencia de fecha 10-XI-2017, Inc. 8-2015, se afirmó que no es imperativo que los mandatos al legislador aparezcan explícitamente en el texto de la Constitución. La jurisprudencia constitucional también puede concretarlos. Ello se justificaría cuando la 
emisión de disposiciones infraconstitucionales es imprescindible para dotar de eficacia plena a una disposición constitucional.

B. El art. 35 del Reglamento Interno del Órgano Ejecutivo atribuye al MJSP, entre otras, las siguientes funciones: (i) elaborar, en coordinación con los organismos que constitucionalmente tienen a su cargo asignadas las tareas relacionadas con la seguridad pública, los planteamientos y estrategias que integren la politica de seguridad pública, debiendo incorporar a estos la prevención de la violencia y del delito, la rehabilitación y reinserción del delincuente y las medidas de represión necesarias para contrarrestar toda actividad delincuencial, con estricto apego a la Constitución y a las leyes secundarias correspondientes; (ii) promover, estimular y fortalecer una cultura de paz y el mantenimiento del orden público por medio de programas permanentes en los que participen los gobiernos locales, organismos no gubernamentales y la ciudadanía en general; (iii) servir como medio de comunicación y coordinación del Órgano Ejecutivo con la CSJ, el Ministerio Público, la Comisión Coordinadora del Sector Justicia y el Consejo Nacional de la Judicatura; (iv) asesorar al Presidente de la República respecto de los proyectos de leyes o de sus reformas relacionados con la politica criminal, las políticas de seguridad pública y la justicia criminal que sean sometidos a su consideración; (v) ejercer, en representación del Presidente de la República y bajo sus directas instrucciones, la organización, conducción y mantenimiento de la PNC y la Academia Nacional de Seguridad Pública; (vi) coordinar con las demás instituciones del Estado la uniformidad de las estadísticas delincuenciales, como base necesaria para el estudio de los factores determinantes de la criminalidad, y crear los organismos que fueren necesarios para las investigaciones criminológicas; (vii) coordinar los esfuerzos nacionales contra el crimen organizado, el lavado de dinero y la corrupción; (viii) coordinar, cuando sea necesario y legalmente pertinente, las acciones de seguridad pública y la elaboración e implementación de las políticas de seguridad pública con las distintas secretarías de Estado que fueren procedentes; y (x) fijar la politica penitenciaria del Estado, de conformidad con los principios que rigen la ley, así como organizar, dirigir, mantener y vigilar los centros penitenciarios, procurando la rehabilitación del recluso y su reinserción en la sociedad.

C. a. La Ley Orgánica de la Comisión Coordinadora del Sector de Justicia atribuye a esta la calidad de "ente coordinador" de dicho sector, cuyos objetivos principales son: (i) analizar la coordinación, al más alto nivel, de las instituciones del mencionado sector; y (ii) definir politicas y estrategias para su desarrollo y decidir sobre los planes, programas y proyectos que deben ser desarrollados en dicho sector.

Para su cumplimiento, la citada ley le confiere como atribuciones: (i) definir, diseñar y ejecutar, por medio de los organismos competentes, la política nacional y estrategias de desarrollo del sector justicia; (ii) promover la coordinación de las instituciones del sector justicia con aquellas que, de alguna manera, se relacionan con actividades de ese sector; (iii) planificar, coordinar, ejecutar, supervisar y evaluar al más alto nivel los planes, programas, proyectos y acciones, que deben ser desarrollados por las instituciones del sector justicia, tendientes a satisfacer necesidades comunes de este y particulares de las instituciones que lo conforman; (iv) aprobar planes para todo 
el sector, así como los planes anuales operativos de cada institución y de la Unidad Técnica Ejecutiva; y (v) estudiar y analizar la problemática de la administración de justicia en sus distintas áreas y cualquier otra especifica relacionada con el sector que, a su juicio, fuere necesario atender.

El art. 4 de la citada ley se refiere a la UTE del Sector de Justicia como la entidad encargada de dar asistencia técnica, administrativa y financiera a la Comisión, en los aspectos indicados con anterioridad, y de supervisar la ejecución de las decisiones y acuerdos de esta. Sus objetivos están definidos en el art. 5, entre los cuales están los siguientes: (i) coordinar y supervisar la ejecución de la politica nacional del sector justicia acordada por la Comisión Coordinadora; (ii) coordinar la planificación, patrocinio, ejecución y asesoría de los planes, programas y proyectos de las instituciones que integran el sector justicia y de las otras entidades públicas y privadas, nacionales e internacionales, que se relacionan con dicho sector; $y$ (iii) supervisar, dar seguimiento y ejecutar los planes, programas, proyectos y acciones del sector justicia.

Sus principales atribuciones, previstas en el art. 6 de la citada ley, son: (i) proporcionar a la Comisión Coordinadora la asistencia técnica, administrativa y financiera en temas de reforma legal y otros; (ii) intervenir en la preparación de los planes, programas y proyectos de las instituciones del sector justicia y de otros organismos o entidades relacionados con dicho sector, supervisar el desarrollo de estos y dar seguimiento a los que se encuentran en ejecución; y (iii) elaborar sus propios planes de acción y aquellos especiales que fueren requeridos por las instituciones del sector.

b. La LEPVT establece en su art. 1 que su objeto es "regular las medidas de protección y atención para las victimas, testigos y cualquier otra persona que se encuentre en situación de riesgo o peligro, como consecuencia de su intervención en la investigación de un delito o en un proceso judicial".

Esta ley contempla medidas de protección y de atención a tres tipos de sujetos: las victimas, los testigos y otras personas que se encuentren en riesgo o peligro por su intervención directa o indirecta en la investigación de un delito o en un proceso judicial o por su relación familiar con la persona que interviene en éstos. Los tipos de medidas contempladas en la ley son los siguientes: (i) medidas de protección ordinarias, que consisten en acciones encaminadas a preservar la identidad y localización de las personas protegidas; (ii) medidas de protección extraordinarias, que consisten en acciones que brindan a las personas protegidas seguridad integral, de manera temporal o definitiva, por condiciones de extremo peligro; (iii) medidas de protección urgentes, que son las medidas ordinarias y extraordinarias que se aplican de manera inmediata y provisional, de acuerdo al riesgo, y que se brindan mientras se decide la aplicación definitiva de estas; y (iv) medidas de atención, que son las acciones complementarias destinadas a preservar la salud física o mental de las personas protegidas, a satisfacer sus necesidades básicas y a proporcionarles asesoría jurídica oportuna.

El art. 5 de la citada ley atribuye a la Comisión Coordinadora del sector justicia la calidad de "ente rector del Programa de Protección de Víctimas y Testigos" y el art. 6 considera a la UTE el "organismo administrador del Programa de Protección de Victimas y Testigos". 
La Comisión, tiene, entre otras, las atribuciones siguientes: (i) aprobar, brindarle seguimiento y evaluar el Programa de Protección de Victimas y Testigos; (ii) evaluar el desempeño de los organismos intervinientes en el programa; (iii) crear los equipos técnicos evaluadores que fueren necesarios por razones del servicio; (iv) someter a la aprobación del Presidente de la República los reglamentos que fueren necesarios para facilitar la ejecución de la referida ley —art. 7 de la ley-.

Por otro lado, el art. 8 letra j: "proponer la celebración de convenios de cooperación y mantener las relaciones a nivel nacional e internacional con organismos e instituciones para facilitar el cumplimiento de la ley. La Unidad Técnica coordinara con el Ministerio de Relaciones Exteriores lo que fuese pertinente".

La UTE tiene por atribuciones: (i) elaborar el Programa de Protección de Víctimas y Testigos y someterlo a la aprobación de la Comisión; (ii) conocer las solicitudes de medidas de protección y atención formuladas por el Órgano Judicial, la FGR, la Procuraduría General de la República, la PNC y el interesado; (iii) identificar, autorizar, implementar, modificar y suprimir las medidas de protección y atención destinadas a las personas que califiquen para recibir los beneficios del programa, debiendo considerar para ello el dictamen de los equipos técnicos evaluadores; (iv) organizar, dirigir y administrar los albergues o casas de seguridad; y (v) encomendar, cuando fuere procedente, la ejecución material de las medidas de protección a la unidad o departamento correspondiente de la PNC o de la Dirección General de Centros Penales.

c. El procedimiento para la aplicación de medidas a favor de las víctimas inicia con la adopción de medidas urgentes por los jueces, la FGR, la Procuraduría General de la República, la PNC y la propia UTE. Posteriormente esta, con el dictamen de los equipos técnicos evaluadores, confirma, modifica o suprime las medidas de protección urgentes que se hubieren adoptado. Las autoridades de las referidas instituciones se encuentran facultadas para requerir la aplicación de medidas ordinarias, extraordinarias y de atención, las cuales deben justificar en la situación de peligro que motiva su solicitud. Posteriormente la UTE analiza y califica la procedencia de la solicitud y requiere a los equipos técnicos el dictamen, en el que se deben analizar y evaluar las condiciones de la solicitud y el riesgo de la persona cuya protección se solicita. Luego de recibir el dictamen de los equipos técnicos, la referida entidad decide la aplicación o no de una o varias de las medidas de protección recomendadas. Las medidas de protección y atención se mantienen mientras persiste la situación que las motivó.

D. a. La Asamblea Legislativa aprobó reformas al Código Penal para prever en su art. 152-A el delito de limitación ilegal a la libertad de circulación -Decreto Legislativo $n^{\circ} 432$, de 27-VII-2016, publicado en el Diario Oficial $n^{\circ} 146$, Tomo 412, del 11-VIII2016-. El tipo penal descrito en el inc. $1^{\circ}$ de la citada disposición establece: "El que, mediante violencia, intimidación o amenaza sobre las personas o los bienes, impida a otro circular libremente, ingresar, permanecer o salir de cualquier lugar del territorio de la República, será sancionado con prisión de cuatro a ocho años". El inc. $3^{\circ}$ contiene una regulación aún más específica que tipifica como delito las acciones violentas que dan lugar al desplazamiento forzado: "Cuando la violencia, intimidación o amenaza 
sobre las personas o los bienes se realizaren para obligar a otro a abandonar su lugar de domicilio, residencia, trabajo, estudios o de realización de cualquier actividad lícita, se impondrá la pena de ocho a doce años de prisión"—itálicas suplidas-.

b. En la Sentencia de fecha 17-VII-2015, Inc. 62-2012, se precisó que el estatuto procesal de la víctima comprende los derechos a la información, asistencia, protección, reparación y participación en las diferentes fases del procedimiento penal, incluida la de ejecución de la condena. El derecho a la protección implica que la víctima está facultada para solicitar y recibir aquellas medidas de protección reconocidas en el ordenamiento procesal penal —art. 106 del C.Pr.Pn._y en los regímenes de protección vigentes - v. gr. la LEPVT_. En consecuencia, las diferentes instancias que componen el sistema de justicia penal están obligadas a brindarle seguridad tanto a ella como a su grupo familiar aun cuando se abstenga de colaborar con el trámite procesal.

c. Si bien la víctima del desplazamiento forzado es considerada sujeto pasivo del delito en el tipo penal previsto en el art. 152-A inc. $3^{\circ}$ del Código Penal, ello es insuficiente para reconocerle y garantizarle la calidad de sujeto de derechos que su propia calidad de victima requiere en el contexto de la investigación y del proceso penal. Además, como víctima de un fenómeno de violencia estructural y sistemática, requiere de medidas reforzadas de protección a su favor.

A esta conclusión llega este Tribunal al analizar la legislación referida a las víctimas, particularmente la LEPVT. Su ámbito de aplicación es anacrónica restringida $y$ deficiente, siendo su objeto principal el otorgamiento de medidas temporales de protección a quienes participan como testigos o víctimas en la investigación de un delito o en el proceso judicial. En definitiva, el enfoque de la legislación de la materia y su aplicación por las autoridades públicas competentes tiene una naturaleza instrumental: la de la víctima como un medio u objeto que coadyuva a la investigación del delito y al procesamiento de los responsables.

De ahí que, a la luz del contexto actual de violencia estructural y sistemática, las personas directamente afectadas por el fenómeno que optan por desplazarse, pero que por temor a sufrir ataques directos no denuncian los delitos de los que han sido víctimas - lo cual no les hace perder esa calidad - no pueden acogerse a las medidas de protección ordinarias y extraordinarias o de asistencia que la ley contempla. Además, la aplicación de dichas medidas no es automática, sino que requiere de un procedimiento en el que se determina la procedencia o no de ellas. De ahi que no toda persona que ha sido víctima de violencia podría acogerse al programa especial de protección de víctimas y testigos por el mero hecho de tener de facto la calidad de desplazado interno.

Si bien las víctimas deben colaborar con la investigación del delito, en el contexto actual de violencia, inseguridad e impunidad, muchas de ellas optan por guardar silencio y se colocan en un nivel de indefensión acentuado. Por ello, es un deber de las autoridades garantizar su protección para que participen voluntariamente en el proceso penal. Además, es necesario que el Estado les provea medidas reforzadas de protección que trasciendan la visión reduccionista que caracteriza a 
la legislación penal y que tomen en cuenta su calidad de desplazados internos a causa de la violencia.

d. Este reconocimiento de la víctima, particularmente en el contexto descrito, como sujeto de derechos, y no como un mero objeto de regulación o instrumento en la investigación del delito, debe ir aparejada de medidas prestacionales —de protección y de asistencia humanitaria- que les garanticen un mínimo de condiciones para una existencia digna mientras se desarrollan las condiciones necesarias para el retorno a sus hogares o su reubicación en otro lugar. Este enfoque también requiere de medidas para evitar que haya nuevas víctimas del fenómeno y para garantizar a quienes ya tienen calidad de desplazado la posibilidad de retorno a sus residencias, pero ello solo será posible previa recuperación de la soberanía territorial en las comunidades dominadas por las pandillas.

e. i. Se advierte que la Asamblea Legislativa no ha llevado a cabo, en el ejercicio de la atribución que le confiere el art. 131 ord. $5^{\circ}$ de la Cn., una actualización de la legislación sobre víctimas que sea acorde con la realidad presente, específicamente, en el sentido de brindar a las víctimas de desplazamiento forzado la protección necesaria para resguardar sus vidas y otros bienes jurídicos igualmente relevantes. Incluso, la Asamblea Legislativa reconoció _ por medio de uno de sus apoderados - en la audiencia probatoria que no existía legislación que reconociera el fenómeno del desplazamiento forzado y que abordara sus causas estructurales o las soluciones que requería.

ii. Por otro lado, las autoridades competentes para intervenir en los procesos de discusión, diseño e implementación de la política pública de seguridad —el MJSP_y de las politicas concretas y protocolos de actuación orientados a la protección de las víctimas -el MJSP y el resto de instituciones que conforman la Comisión Coordinadora del Sector de Justicia - han omitido cumplir el mandato que les atribuye la Ley Orgánica de la referida comisión y la LEPVT de diseñar politicas especiales y reforzadas para la protección de las víctimas, particularmente las de desplazamiento forzado, a la luz del contexto actual de violencia al que se ha hecho referencia.

Es preciso reconocer los esfuerzos que dichas instituciones han desarrollado para fortalecer sus ámbitos de acción: convenios institucionales para proporcionar alimento y medios de trabajo a las victimas que permanecen en los albergues; medidas de protección ordinarias, extraordinarias y de asistencia a un alto porcentaje de víctimas que colaboran con la investigación del delito; capacitaciones y revisión de la legislación penal y procesal penal, entre otros. Sin embargo, aquellas manifestaron en sus informes que uno de los impedimentos para ampliar el programa de protección de víctimas y testigos es la insuficiencia del presupuesto que se les asigna anualmente.

No es el objeto de esta sentencia valorar los informes de labores de dichas instituciones, sino pronunciarse sobre el cumplimiento o no de una de sus competencias: diseñar politicas y protocolos de actuación orientados a brindar protección a las victimas. Dichas instituciones no acreditaron el cumplimiento de esa labor y su omisión contribuye 
a prolongar la situación de vulnerabilidad de las víctimas de la violencia que atraviesa el país, en particular los desplazados internos.

iii. En lo que atañe a la politica de seguridad a cargo del MJSP, si bien dicha institución es la encargada de implementar el Plan El Salvador Seguro, en cuyo eje $n^{\circ} 4$ se describen las lineas generales de la protección a víctimas, es renuente a incluir en la categoría de "victimas" a los desplazados internos. La referida institución, en su informe sobre "movilidad humana", dictamina un porcentaje minimo de personas desplazadas por la violencia que el fenómeno de desplazamiento forzado, distinto al que señalan otras instituciones como la PDDH y la Relatora Especial sobre los derechos humanos de los desplazados internos de Naciones Unidas.

Si bien el MJSP ha elaborado un anteproyecto de Ley Especial para la Atención, Protección y Reparación Integral a Víctimas del Delito y Violencia, cuyo objeto es más amplio que el de la LEPVT y define a la víctima con una perspectiva amplia, tampoco contiene un enfoque integral de las víctimas de desplazamiento forzado ni ha sido presentado aún a la Asamblea Legislativa para su discusión.

E. Con base en lo expuesto, se concluye que el incumplimiento de las atribuciones antes descritas por la Asamblea Legislativa, por el MJSP, por la Comisión Coordinadora y por la titular de la UTE del Sector de Justicia, motivado por la falta de reconocimiento del fenómeno del desplazamiento forzado y de las dimensiones de la violencia que afecta a los territorios controlados por las pandillas, vulnera a las víctimas de este fenómeno - entre las cuales se encuentran los demandantes - los derechos a la protección en la conservación jurisdiccional y no jurisdiccional de los derechos, a la seguridad material, a la protección de la familia, a las libertades de circulación y de residencia y a la propiedad. Por consiguiente, es procedente declarar que ha lugar el amparo requerido por los pretensores en contra de las autoridades antes mencionadas.

VII. Determinadas las transgresiones constitucionales derivadas, por una parte, de la falta de investigación de los hechos denunciados por los peticionarios ante autoridades policiales y, por otra parte, de las omisiones de la Asamblea Legislativa, del MJSP, de la Comisión Coordinadora y de la UTE del Sector de Justicia de revisar y actualizar la normativa sobre víctimas y diseñar e implementar politicas para la protección y la atención humanitaria de los desplazados, corresponde establecer el efecto de esta decisión.

1. El art. 35 inc. $1^{\circ}$ de la L.Pr.Cn. establece que el efecto material de la sentencia de amparo consiste en ordenarle a la autoridad demandada que las cosas vuelvan al estado en que se encontraban antes de la vulneración constitucional. Pero, cuando dicho efecto ya no sea posible, la sentencia de amparo será meramente declarativa, quedándole expedita al amparado la promoción de un proceso en contra del funcionario personalmente responsable.

En efecto, de acuerdo con el art. 245 de la Cn., los funcionarios públicos que, como consecuencia de una actuación u omisión dolosa o culposa, hayan vulnerado derechos constitucionales deberán responder, con su patrimonio y de manera personal, de los daños materiales y/o morales ocasionados. En todo caso, en la Sentencia de 15-II-2013, 
Amp. 512011, se aclaró que, aun cuando en una sentencia estimatoria el efecto material sea posible, el amparado siempre tendrá expedita la incoación del respectivo proceso de daños en contra del funcionario personalmente responsable, en aplicación directa del art. 245 de la Cn.

2. A. En el presente caso, en cuanto a la vulneración de los derechos a la protección en la defensa jurisdiccional y no jurisdiccional, el efecto reparador se concretará en ordenar al Director de la PNC y al titular de la FGR, como máximas autoridades de esas instituciones, que realicen investigaciones exhaustivas, diligentes y concluyentes, con el fin de esclarecer los delitos de los cuales supuestamente fueron víctimas los peticionarios cuando residían en el municipio de Delgado y en el municipio de Berlín. Si determinan que existen suficientes indicios sobre los delitos que señalan los actores, deberán ejercer de inmediato la acción penal, a fin de que oportunamente se realice un juicio inmediato, independiente e imparcial en el que se sancione a los autores intelectuales y materiales de los mismos.

B. a. No se debe perder de vista que los desplazamientos forzados de población provocados por la coacción de las pandillas ocasionan el desarraigo de contingentes de personas $y$, por consiguiente, la imposibilidad de que estas puedan vivir en paz, en libertad y con seguridad en sus lugares de residencia. Resulta claro que estos hechos socavan la función del Estado de garantizar la libertad de residencia, la seguridad material y la convivencia pacífica de la población asentada en su territorio y que existen agrupaciones delictivas que ejercen coacciones ilegítimas a una escala masiva que erosiona de igual forma el monopolio de la violencia física ejercido por el Estado.

Estos desplazamientos internos se llevan a cabo en espacios urbanos y rurales controlados por las pandillas, en los que no se advierte la presencia del Estado. No solo cabe destacar la ausencia de la fuerza pública en dichos territorios, sino también la de las instituciones públicas encargadas de ejecutar las políticas sociales que podrían coadyuvar a reconstituir los tejidos sociales desgarrados por la violencia. El vacío que en los territorios controlados por las pandillas ha dejado la deficitaria presencia de las diversas instituciones del Estado ha sido ocupado por las agrupaciones delictivas que, con estos desplazamientos, confirman que la ausencia de poderes públicos da lugar a que los más fuertes impongan su voluntad a los más débiles.

b. En el presente proceso se comprobó que los demandantes forman parte de un colectivo de personas que, ante la nula o deficiente protección por parte de las autoridades públicas, se vieron forzadas a desplazarse a causa de la violencia sistemática generada principalmente por las pandillas. Por ello, se estimó la pretensión planteada por aquellos en relación con la vulneración de sus derechos fundamentales a la protección en la conservación jurisdiccional y no jurisdiccional de los derechos, a la seguridad material, a la protección de la familia, a las libertades de circulación y de residencia, y a la propiedad. 
Las omisiones de las autoridades competentes de adecuar el ordenamiento jurídico al contexto descrito en este pronunciamiento y de diseñar la politica de seguridad y protocolos de actuación para la protección de las víctimas de la violencia coadyuvaron a que su situación de indefensión y de vulnerabilidad se prolongara en el tiempo y a que sus derechos continuaran siendo transgredidos por grupos criminales que de facto controlan el territorio de sus comunidades.

Estas omisiones derivaron de la persistencia de las autoridades del Estado con competencia en materia de seguridad pública en minimizar el fenómeno de desplazamiento forzado, del no reconocimiento de los desplazados como víctimas de una situación de violencia sistemática y estructural y de la denegatoria a estos sujetos de sus derechos a una protección reforzada y a la asistencia humanitaria necesaria para disfrutar de condiciones de vida mínimas para una existencia digna. Lo anterior afecta a la totalidad de personas desplazadas por el fenómeno de la violencia.

Ello habilita a este Tribunal, como guardián de la Constitución, a emitir un pronunciamiento que trascienda el efecto inter partes con el objeto de remediar una situación generalizada que afecta de manera directa los derechos fundamentales.

C. En consecuencia, es procedente ordenar a la Asamblea Legislativa, al titular del MJSP, a la Comisión Coordinadora y a la titular de la UTE que, conjuntamente con los demás órganos y entidades del Estado, cumplan con las siguientes obligaciones: (i) reconocer a las personas referidas la calidad de víctimas de dicho fenómeno y de sujetos de derechos y categorizarlos normativamente, para lo cual es necesaria la revisión de la legislación especial orientada a la protección de víctimas y testigos; (ii) diseñar e implementar políticas públicas y protocolos de actuación orientados a prevenir el desplazamiento forzado de los habitantes del país, por lo que es urgente que se adopten medidas para recobrar el control territorial de las zonas dominadas por las pandillas y evitar futuros desplazamientos y la continuidad de las afectaciones sistemáticas a derechos fundamentales; y (iii) brindar medidas de protección a quienes ya tienen de facto la condición de desplazados y, además, garantizarles la posibilidad de retorno a sus residencias.

D. Las anteriores medidas de protección requieren de una optimización de los recursos por parte de las dependencias del Estado que participan en el proceso de prevención y atención del fenómeno de violencia. La presencia del Estado, orientado a la realización de la persona humana y sus fines, y la recuperación del control territorial en las comunidades afectadas por la criminalidad organizada deben ir acompañadas de medidas de prevención y control de dicho fenómeno. Además, se debe fortalecer a las instituciones encargadas de la seguridad pública y de la investigación del delito. Estas medidas deben ser ejecutadas con carácter urgente debido a la situación de riesgo en la que se encuentran las víctimas de la violencia y de desplazamiento forzado. Por ello, debe ordenarse también al Presidente de la República que: (i) coordine con los titulares de las distintas dependencias que integran el Órgano Ejecutivo (justicia y seguridad pública, PNC, educación, salud, hacienda e inclusión social, entre otras) la realización de las acciones necesarias para prevenir y 
controlar el fenómeno de la violencia, mediante, por un lado, la formulación y ejecución de las políticas sociales que eviten la marginación de sectores vulnerables en la sociedad y, por otro, la implementación de acciones orientadas a recobrar progresivamente y de forma permanente los territorios bajo control de las pandillas; y (ii) incluya la atención a las víctimas de desplazamiento forzado por la violencia como una prioridad en la elaboración del presupuesto general del Estado.

E. Para garantizar a las víctimas de la violencia y del desplazamiento forzado una reparación progresiva de las afectaciones causadas a sus derechos es indispensable reconocer que en El Salvador existe un fenómeno de desplazamiento forzado de personas que tiene origen en el contexto de violencia e inseguridad que afecta gravemente a colectivos vulnerables de distintas zonas geográficas del país controladas por las pandillas y en las afectaciones sistemáticas a derechos fundamentales como la vida, la integridad física, la libertad y la propiedad, entre otros, causadas por la criminalidad organizada, principalmente por los referidos grupos delictivos; por lo que así se hará constar en el fallo de esta sentencia.

Esta Sala dará seguimiento al cumplimiento de la presente sentencia por medio de informes periódicos y audiencias, entre otros.

3. Finalmente, en atención a los arts. 245 de la Cn. y 35 inc. $1^{\circ}$ de la L.Pr.Cn., los actores de estos procesos tienen expedita la promoción de un proceso por los daños materiales y/o morales resultantes de las vulneraciones de derechos constitucionales declarada en esta sentencia directamente en contra de las personas responsables de estas.

POR TANTO: con base en las razones expuestas y lo prescrito en los arts. 2, 5, 32 y 245 de la Cn., así como en los arts. $31 n^{\circ}$ 3, 32, 33, 34 y 35 de la L.Pr.Cn., a nombre de la República, esta Sala FALLA: (a) Declárase que en El Salvador existe un fenómeno de desplazamiento forzado de personas que tiene origen en el contexto de violencia e inseguridad que afecta gravemente a colectivos vulnerables de distintas zonas geográficas del país controladas por las pandillas y en las afectaciones sistemáticas a derechos fundamentales como la vida, la integridad física, la libertad y la propiedad, entre otros, causadas por la criminalidad organizada, principalmente por los referidos grupos delictivos, lo cual constituye un estado de cosas inconstitucionales; (b) Sobreséese en el presente amparo a la jefa de la Unidad de Vida de la Oficina Fiscal de Mejicanos, por la falta de legitimación pasiva en relación con la vulneración constitucional que le fue atribuida por los peticionarios; no obstante, el titular de la FGR deberá deducir las responsabilidades administrativas derivadas de la falta de diligencia $y$, en caso de ser posible, promover la vía de reparación de los derechos fundamentales de las víctimas; (c) Declárase que ha lugar el amparo solicitado por los Demandantes 1, 2, 3, 4, 5 y 6 contra el jefe de la División Central de Investigaciones, el jefe de la División Antiextorsiones, el jefe de la Subdelegación de Berlín, departamento de Usulután, todos ellos de la PNC, por la vulneración de sus derechos a la protección en la defensa jurisdiccional y no jurisdiccional de los derechos, 
a la seguridad material, a la protección familiar, a las libertades de circulación y de residencia, y a la propiedad; (d) Declárase que ha lugar el amparo solicitado por los referidos demandantes en contra de la Asamblea Legislativa, el Ministro de Justicia y Seguridad Pública, la Comisión Coordinadora y la directora de la Unidad Técnica Ejecutiva del Sector de Justicia por la vulneración de sus derechos a la protección en la conservación jurisdiccional y no jurisdiccional de los derechos, a la seguridad material, a la protección familiar, a las libertades de circulación y de residencia, y a la propiedad; (e) Ordénase al Director de la PNC y al titular de la FGR, como máximas autoridades de esas instituciones, que realicen de manera inmediata investigaciones exhaustivas, diligentes y concluyentes, con el fin de esclarecer los delitos de los cuales supuestamente fueron victimas los peticionarios cuando residian en los municipios de Delgado y de Berlin; (f) Ordénase a la Asamblea Legislativa, al Ministro de Justicia y Seguridad Pública, a la Comisión Coordinadora y a la titular de la Unidad Técnica Ejecutiva del Sector de Justicia que en el plazo de seis meses cumplan con lo siguiente: (i) reconocer a las víctimas de la violencia y del desplazamiento forzado dicha calidad, como sujetos de derechos, y categorizarlos normativamente, para lo cual se deberá revisar y emitir la legislación especial orientada a la protección de víctimas y testigos; (ii) diseñar e implementar políticas públicas y protocolos de actuación orientados a prevenir el desplazamiento forzado de los habitantes del país, por lo que deberán promover y adoptar —en el marco de sus competencias - medidas para recobrar el control territorial de las zonas dominadas por las pandillas y evitar futuros desplazamientos y la continuidad de las afectaciones sistemáticas a derechos fundamentales; (iii) brindar medidas de protección a quienes ya tienen de facto la condición de desplazados y, además, garantizarles la posibilidad de retorno a sus residencias; y (iv) celebrar los convenios de cooperación a nivel nacional e internacional para asegurar la protección de víctimas y testigos. El anterior tratamiento deberá otorgarse independientemente si los casos estan judicializados; (g) Ordénase al Presidente de la República que dé cumplimiento a lo siguiente: (i) coordine con los titulares de las distintas dependencias que integran el Órgano Ejecutivo (justicia y seguridad pública, PNC, educación, salud, hacienda e inclusión social, entre otras) la realización de las acciones necesarias para prevenir y controlar el fenómeno de la violencia, mediante, por un lado, la formulación y ejecución de las políticas sociales que eviten la marginación de sectores vulnerables en la sociedad y, por otro, la implementación de acciones orientadas a recobrar progresivamente y de forma permanente los territorios bajo control de las pandillas; y (ii) incluya la atención a las víctimas de desplazamiento forzado por la violencia como una prioridad en la elaboración del presupuesto general del Estado; (h) Queda expedita a los Demandantes 1, 2, 3, 4, 5 y 6 la promoción de un proceso por los daños materiales y/o morales que les han sido ocasionados, directamente en contra de las personas responsables de las vulneraciones constitucionales constatadas en esta sentencia; (i) Extiéndanse a los abogados Sergio Ernesto Chicas Mejía, como apoderado de la Asamblea Legislativa, María Cristina Martinez y Carlos Alfredo Valiente, como apoderados de la PNC, y German Oliverio Rivera Hernández, como apoderado de la 
Comisión Coordinadora y de la UTE del Sector de Justicia las copias de los documentos y medios de almacenamiento requeridos, a costa de los peticionarios, quienes deberán guardar la debida confidencialidad sobre su contenido, en virtud de la reserva ordenada en este proceso; $y$ (j) Notifíquese.

\section{Nota}

1 La sentencia ganó el primer lugar del "Premio Regional de Sentencias Acceso a la Justicia de Personas Migrantes o Sujetas de Protección Internacional", que organiza ACNUR, Sin Fronteras, CIDH, entre otras, concursando con otras 47 sentencias de Argentina, Brasil, Colombia, Chile, Costa Rica, Ecuador, Honduras y México.

Abraham A. Abrego Hasbún. Salvadoreño. Obtuvo su título de Licenciado en Ciencias Jurídicas con la Universidad Centroamericana "José Simeón Cañas", El Salvador. Se desempeñó como coordinador de oficina de asistencia legal del Instituto de Derechos Humanos de la Universidad Centroamericana y como director de la Fundación de Estudios para la Aplicación del Derecho. Se desempeña actualmente como director de acompañamiento a víctimas de Cristosal. Ha formado parte de iniciativas ciudadanas de apoyo y defensa de los derechos de víctimas.

Contacto: abraham.abrego@cristosal.org

ORCID: 0000-0002-9159-6852 